\title{
Targeting Catholic Rituals as Symptoms of Obsessive Compulsive Disorder: A Cognitive-Behavioral and Psychodynamic, Assimilative Integrationist Approach
}

\author{
HECTOR A. GARCIA ${ }^{\text {a,b,c }}$
}

${ }^{\text {a }}$ Audie L. Murphy Memorial Veterans Hospital, San Antonio, TX

b Correspondence concerning this article should be addressed to Hector A. Garcia, OEF/OIF Program, PTSD Team, South Texas Veteran's Health Care System, Audie L. Murphy Memorial Veterans Hospital, Frank Tejeda Outpatient Clinic, 5788 Eckhert Road, San Antonio, Texas 78240.

Email: Hector.Garcia2@va.gov

${ }^{\mathrm{C}}$ The author is a graduate of the Graduate School of Applied and Professional Psychology of Rutgers University

\begin{abstract}
"Bridget” was my first cognitive behavioral therapy (CBT) case and assigned to me in my second year of doctoral training as part of a clinical practicum. She was a 21-year-old undergraduate student who presented with depression and obsessive-compulsive disorder (OCD), in which the obsessions were religious in nature and the compulsions were rituals of the Catholic religious tradition, such as crossing and praying. Distinguishing between thoughts and behaviors that would be targeted as symptoms and those that would be retained as bona fide religious beliefs - and thus not viewed as a function of Bridget's OCD - presented unique ethical and technical challenges. In Phase 1 of treatment I used cognitive-behavioral therapy (CBT) methods to target Bridget's OCD symptoms. After these obsessions and compulsions had been virtually eliminated using the CBT-oriented treatment, Bridget was eager to pursue other difficulties (such as the impact of her interpersonal style on her relationships with men). At this time I had the opportunity to continue therapy with Bridget in conjunction with a psychoanalytic course I was taking that offered a psychodynamic supervisor. I determined that this Phase 2 arrangement would be in Bridget's therapeutic interests in light of: (a) the issues with which she was dealing; (b) the fact that Bridget and I had established an excellent working relationship during Phase 1 and Bridget easily agreed to continue therapy with me in the new, less structured, psychodynamically oriented format; and (c) the fact that the new, psychodynamic supervisor was open to my integrating psychodynamic concepts into the CBT approach I had employed in Phase 1. Overall, therapy was conducted weekly during $2 \frac{1}{2}$ academic years (the client generally took the summers off) for a total of 79 sessions. The therapy results across the two phases present evidence that in the context of the above-mentioned facilitating conditions, the two phases worked smoothly together to help Bridget with the variety of problems she presented.
\end{abstract}

Keywords: cognitive-behavioral therapy; obsessive-compulsive disorder; Catholic rituals; scrupulosity; psychodynamic therapy; assimilative integration 
Targeting Catholic Rituals as Symptoms of Obsessive Compulsive Disorder:

A Cognitive-Behavioral and Psychodynamic, Assimilative Integrationist Approach

H.A. Garcia

Pragmatic Case Studies in Psychotherapy, http://pcsp.libraries.rutgers.edu

Volume 4, Module 2, Article 1, pp. 1-38, 05-12-08 [copyright by author]

\section{CASE CONTEXT AND METHOD}

"Bridget” was my first cognitive behavioral therapy (CBT) case and assigned to me in my second year of doctoral training as part of a clinical practicum. (Note that the client's name and all other identifying information have been changed to disguise the client's identity.). There were two phases to the therapy. Phase 1 consisted of 27 sessions of CBT to successfully address the client's obsessive-compulsive disorder (OCD) symptoms, and it was supervised by Dr. William Sanderson, who follows a CBT model.

At the end of Phase 1, while Bridget's obsessions and compulsions had been virtually eliminated, she was strongly motivated to pursue other difficulties, particularly a history of troubled relationships with men and a rapid, pressured, and scattered style of speech that interfered in how she communicated with important people in her life. At the same time, I was taking a course on psychodynamic therapy that provided me an opportunity to see a client using this modality with a psychodynamic supervisor. I determined that this Phase 2 arrangement would be in Bridget's therapeutic interests in light of three factors: the interpersonal nature of the issues with which she was dealing; the fact that Bridget and I had established an excellent working relationship during Phase 1 and Bridget easily agreed to continue therapy with me in the new, less structured, psychodynamically oriented format; and the fact that the new, psychodynamic supervisor was open to my integrating psychodynamic concepts into the CBT approach I had employed in Phase 1. Thus, one of the emergent themes in the case is how well the two guiding conception models that I was striving to integrate would therapeutically work in Bridget's case.

Several years after treatment I called Bridget describing to her my interest in writing up her case for publication in a scholarly journal. She eagerly agreed and signed a consent form, which states that proper disguise of identifying characteristics would be observed.

\section{THE CLIENT}

Bridget, a 21 year-old Caucasian woman of European descent, was self-referred to the training clinic of a university-based, clinical psychology doctoral program. She came to the clinic complaining of anxiety and depression and stated that these feelings were impeding the performance of her daily routine at school. Bridget is Catholic, but described being fairly liberal in her religious beliefs. She reported being heterosexual and that she was a virgin. When she started the treatment, she was a sophomore at the university. She reported having been in psychodynamic therapy in high school for one year and CBT as a college freshman for three months, both for the treatment of anxiety. Assessment revealed that her anxiety consisted primarily of obsessive rumination and ritualizing.

Bridget was raised in a city in the northeast United States by both parents. She has two brothers (one older, one younger) and a large and close, extended Catholic family. She denied a history of abuse or neglect. Bridget described her father, a successful businessman, as a strong but kind man who functioned as the moral grounding for the family, and she said that it was often to him that she and many in her family turned for support and advice. He died of cancer 
when she was 14 . Though she denied a family history of mental illness, Bridget depicted her mother as an anxious woman who avoided emotional stimulation, including discussions of the death of her father. Perhaps as a consequence of this, Bridget always had an emotionally closer relationship with her father. In therapy she relayed memories of long conversations with him every night before bed. Accordingly, she stated that he was a strong presence in her life and an important source of guidance and inspiration. Bridget also had a close relationship with her younger brother.

During her father's protracted illness Bridget began engaging in ritualistic behaviors such as counting, praying, or making the sign of the cross - in order to prevent his condition from further deteriorating. When her father finally passed away, her symptoms worsened and she was left with feelings of guilt stemming from the irrational belief that she could have ritualistically prevented his death. The guilt was compounded by the fact that in the weeks preceding his passing she felt she had orchestrated numerous arguments with him. She reported that although the loss of her father affected her very deeply, her age and immaturity as a 14-yearold prevented her from ever fully appreciating the finality of his death. As such, for years she sensed the lingering presence of unexpressed grief churning under the surface of her daily living. One year after her father's death Bridget began experiencing depressive symptoms.

At the time when Bridget came in for treatment, she was having obsessive thoughts, which revolved around sexual and moral issues, fears of accidentally harming others, and irrational feelings of responsibility for the well-being of others. To alleviate the distress generated by these preoccupations, she compulsively prayed, crossed herself, and kneeled — all in a ritualistic manner not associated with an established religious convention. She also engaged in counting and checking behaviors (e.g., locks/stoves), and tapped her fingers ritualistically. In response to moral or sexual ruminations, she attempted to make herself feel guilty — apparently as a means of atonement — by ritualistically looking up to the sky toward God. If she failed to perform these rituals, she feared she was either being selfish, morally reproachable, or was somehow the cause of the misfortune of others. She realized that both the obsessions and compulsions were excessive and unreasonable and reported a great deal of frustration about the symptoms she experienced.

\section{GUIDING CONCEPTION}

\section{Phase 1}

While OCD, as reflected in the symptoms with which Bridget initially presented, has historically been considered one of the most intractable psychological disorders, recent advances in treatments, particularly various forms of cognitive-behavioral therapy, have yielded encouraging results toward reducing symptoms and in managing the disorder (Riggs \& Foa, 1993). These treatments generally look at obsessions and compulsions as dysfunctional ways to manage anxiety that can be addressed by (a) trying to reduce the anxiety per se or the avoidance of anxiety via exposure to some version of the anxiety-provoking stimuli, e.g., through systematic desensitization, or through direct exposure and response prevention of compulsive behaviors in the presence of the anxiety-provoking stimuli; and/or by (b) trying to understand 
Targeting Catholic Rituals as Symptoms of Obsessive Compulsive Disorder:

A Cognitive-Behavioral and Psychodynamic, Assimilative Integrationist Approach

H.A. Garcia

Pragmatic Case Studies in Psychotherapy, http://pcsp.libraries.rutgers.edu

Volume 4, Module 2, Article 1, pp. 1-38, 05-12-08 [copyright by author]

and challenge the automatic thoughts and underlying beliefs that "justify" and perpetuate the anxiety, e.g., through cognitive restructuring. Initial behavioral techniques varied in their effectiveness. Systematic desensitization was only moderately successful (Beech \& Vaughn, 1978), as were early attempts at prolonged exposure (Riggs \& Foa, 1993). Thought stopping was found to be ineffectual in several cases (Emmelkamp \& Kwee, 1977; Stern, 1978; Stern Lipsedge \& Marks, 1975), while applying punishment — such as electrical shocks — was somewhat more successful (Kenny, Mowbray \& Lalani, 1978).

Exposure and response-prevention (ERP) have fared far better, and they are the most studied and generally considered the most effective treatment combination, with results enduring after followup (for a review see Foa, Steketee \& Ozarow, 1985). While exposure and responseprevention combined tend to be more effective than either technique alone, obsessional distress tends to be more responsive to exposure, whereas response-prevention has the most impact on ritualistic behaviors (Foa, Steketee, \& Milby, 1980). Foa, Steketee, Turner and Fischer (1980) found that while there were no differences in effect between in vivo and imaginal exposure, combining the strategies was better at preventing relapse. Riggs and Foa (1993) argue that starting with the least distressing stimuli is not directly related to the effectiveness of ERP, but that patients usually prefer starting with the least distressing, which in turn reduces drop-out rates. While long exposures are more effective than brief exposures (Rabavilas, Boulougouris, \& Stefanis, 1976), clinical observation shows that discomfort during exposure begins to attenuate after 30 minutes, but can last for 90 minutes (Foa \& Chambless, 1978). Riggs and Foa (1993) therefore advise that prolonged exposure interventions be no less than 45 minutes.

Cognitive interventions such as cognitive restructuring have been shown to work as effectively as ERP (Emmelkamp \& Beans, 1991). However, reviews of controlled studies comparing cognitive therapy and ERP have revealed overlapping procedures (Abramowitz, 1997).

Based on the above evidence for the effectiveness of ERP and cognitive restructuring in the treatment of OCD, I chose these two as the major treatment strategies in Phase 1 in working with Bridget's obsessions and compulsions. Specifically, I followed the treatment manual written by McGinn \& Sanderson (1999).

\section{Phase 2}

As mentioned above, the main complex of symptoms targeted during the Phase 1 consisted of religious obsessions and compulsions, including crossing and praying in response to religious obsessions. Once these obsessions and compulsions had been virtually eliminated in Phase 1 through CBT-based procedures, Bridget still had problems in two areas that she wanted to work on: (a) a tendency to be attracted to high-status men who were ultimately unattainable, leading to eventual rejection,; and (b) a rapid, pressured, and scattered style of speech, interfering with her ability to effectively communicate with not only me, but important others in her life. Both of these problems seemed to derive in a number of ways from the same cognitive and emotional dynamics that had led to her original obsessions and compulsions. At this time I was taking a course on psychodynamic therapy and needed to see a client using this modality. Even 
though Bridget's Phase 2 goals could have been approached with CBT strategies, there also seemed to be a role for psychodynamic concepts and strategies to be employed with these two goals. This arrangement was facilitated by two important contextual conditions. First, during the first 27 sessions of Phase 1, Bridget and I had established an excellent working relationship, and she was motivated to continue working with me on the Phase 2 problems within a somewhat different model. Second, Dr. James Mandala, my supervisor in Phase 2, while psychodynamically oriented, was open to my integrating psychodynamic concepts into the CBT approach I had employed in Phase 1. Below is a description of the psychodynamic model and how it was integrated with the initial CBT model I was using.

\section{The Psychodynamic Model Employed}

Generally, the psychodynamic approach I employed followed the broadly-defined, object-relations approach described by Skean in an earlier case study in this journal (Skean, 2005). In line with this model, the major concepts and strategies employed include:

A. The use of the therapeutic relationship. The therapeutic encounter is viewed as a vehicle for observing and understanding the client's interpersonal behavior (Strupp \& Binder, 1984; Spence, 1982) since it "allows the therapist to experience aspects of the client's structuring of reality” (Skean, p.3, 2005). In addition,

The supportive, empathic aspects of the relationship "hold" the person in the treatment, providing experiences that may be new to the client, while the more interpretive aspects use the relationship to encourage reflection on the way the client has structured and made meaning of the world (Skean, 2005, p.3).

\section{B. Defenses and Transference. In Skean's words:}

Each person selectively shapes and makes sense of his or her experience, accepting and integrating some of it, and hiding other parts to avoid painful feelings. Much of this occurs outside of awareness (is "unconscious”). The shaping is guided and reinforced by three dynamic elements: unexamined assumptions, unconscious conflicts, and previously developed templates ("transferences") for personal relationships. Problems arise when these dynamic elements limit a person's ability to function effectively, impairing capacities to love and to work productively. Paul Wachtel's (1997) concept of "cyclical psychodynamics" views a negative template as stimulating client behaviors that elicit the very negative behaviors from others that the client expects, thus both confirming the negative template and failing to let in experiences that might disconfirm it.

Through the examination of client transference and therapist countertransference, through the attention to the operation of characteristic defense mechanisms, and by having an interpersonal experience in the therapy that differs from others he or she may have known, the client is encouraged to expand his or her understanding of self in a way that provides more options and choices ( . . . McWilliams, 2004, 1999; Vaillant, 1993, 1977) (Skean, 2005, p.3). 
Targeting Catholic Rituals as Symptoms of Obsessive Compulsive Disorder:

A Cognitive-Behavioral and Psychodynamic, Assimilative Integrationist Approach

H.A. Garcia

Pragmatic Case Studies in Psychotherapy, http://pcsp.libraries.rutgers.edu

Volume 4, Module 2, Article 1, pp. 1-38, 05-12-08 [copyright by author]

C. Importance of the Life History. The psychodynamic model emphasizes the importance of collecting a detailed psychological and social history of the client's life.

D. Support-Oriented Strategies and Insight-Oriented Strategies. In the model, a balance is sought between (a) support-oriented strategies, involving empathic validation of the client's "personhood, life struggles, and suffering” (Skean, 2005, p.4); and (b) insight-oriented strategies, which "challenge defenses and maladaptive transference schemas with alternative and more adaptive interpersonal experiences, both within the therapeutic relationship itself and in the client's outside life" (Skean, 2005, p.4). The goal is to adjust the balance between the two contrasting strategies based upon the client's needs and circumstances as they emerge and evolve within the therapy. While empathic validation and exploring interpersonal schema were certainly in operation in Phase 1, in Phase 2 allowed for a different and uniquely useful manner of using these factors to engender change, as described below.

Integrating the Psychodynamic Model with the CBT Model

Much has been written about combining methods from different theoretical schools. Schacht (1984) outlined four different models commonly assumed in therapy integration. A complementary approach consists of employing techniques from different theoretical backgrounds to deal with different problems in the same patient. An example of this would be using ERP for OCD, and psychoanalytic therapy for identity issues. Another example is Lazarus’s (1992) “technical eclecticism” model, which de-emphasizes theoretical bases and borrows techniques across theoretical orientations based on the nature of the client's specific difficulties. A synergistic approach is one in which differing techniques are applied to the same target and are expected to interact in ways clinically superior to either technique alone. A translational approach involves the basic translation of concepts from one theory to another. One example would be describing the exploration of the dynamics of a patient's family of origin (a mainstay of psychodynamic treatment) in terms of describing the conditions of a patient's learning history (a mainstay of CBT). Finally, an emergent approach takes place when differing techniques combine to produce a hybrid with novel characteristics and applications not found in either technique alone.

As a variation on the emergent approach, Arkowitz (1997) has argued that purportedly emergent therapeutic integration is typically not so emergently integrative, that most integrationists seem to work from the perspective of a single approach that allows for the assimilation of other ideas. Messer (1992) has referred to this importation of concepts as "assimilative integration." In assimilative integration, a practitioner is firmly rooted in at least one orientation, but allows for a meaningful dialogue with the perspectives or techniques from others.

In my second phase of therapy with Bridget, I saw my work as involving all the above approaches at different times, but primarily the assimilative integration model as described by Messer. Within this assimilative model, the primary conceptual grounding of my work with Bridget was CBT, to maintain continuity with Phase 1. Although issues such as transference, countertransference, and object relations were addressed during this phase in a relatively 
Targeting Catholic Rituals as Symptoms of Obsessive Compulsive Disorder:

A Cognitive-Behavioral and Psychodynamic, Assimilative Integrationist Approach

H.A. Garcia

Pragmatic Case Studies in Psychotherapy, http://pcsp.libraries.rutgers.edu

Volume 4, Module 2, Article 1, pp. 1-38, 05-12-08 [copyright by author]

unstructured format, explanations of these concepts were operationalized and often described using CBT terminology, similar to the translative operation described by Schacht. However, there were times at which I switched from CBT to perform operations from a different theoretical orientation entirely, with more conscious emphasis on the technique itself, such as when I addressed issues of transference and countertransference within the therapeutic relationship. In this fashion my work shifted at times to a mode more characteristic of technical eclecticism. The integrative approach more generally, I feel, allowed for artful flexibility in pace, tempo, and timing, which lent itself better to the emotional valence and understanding of interventions, while maintaining the precision and instrumentality of CBT.

\section{ASSESSMENT OF THE CLIENT'S PROBLEMS, GOALS, STRENGTHS, AND HISTORY}

\section{Qualitative Assessment}

In clinically interviewing Bridget, I learned that Bridget’s obsessive thoughts revolved around sexual and moral issues, fears of accidentally harming others, and irrational feelings of responsibility for the well being of others. To alleviate the distress generated by these preoccupations, she prayed, crossed herself, and kneeled-all in a ritualistic manner not associated with an established religious convention. She also engaged in counting and checking behaviors (e.g., locks/stoves), and tapped her fingers in a ritualistic manner. In response to moral or sexual ruminations, she attempted to make herself feel guilty-apparently as a means of atonement - by ritualistically looking up to the sky toward God. If she failed to perform these rituals she feared she was either being selfish, morally reproachable, or was somehow the cause of the misfortune of others. She realized that both the obsessions and compulsions were excessive and unreasonable, and she reported a great deal of frustration about the symptoms she experienced.

There were numerous examples of the symptoms described above. For instance, at a restaurant where Bridget worked as a waitress she had a recurring fear of accidentally poisoning her customers. Accordingly, she checked the containers of cleaning solvents stored in the kitchen cabinets to ensure she did not inadvertently powder the food she served with a lethal garnishing of chemicals. Despite the fact that her position never involved contact with the solvents, making her involvement in such a fatal faux pas a virtual impossibility, she was tormented by the idea and correspondingly checked the containers at almost every order. As her symptoms exacerbated she checked repeatedly. She also engaged in stove and lock checking, which she performed with a similar ardor, sometimes checking fifteen times before leaving the house.

Another behavior occurred upon the passing of ambulances. When hearing the sound of ambulance sirens she dropped whatever she was doing, crossed herself several timessometimes a specific number of times - or looked to the sky. If driving, this often required pulling over to the side of the road either to cross or to pray with clasped hands for the ambulance passenger. If she was unable to perform these behaviors, she felt anxious and guilty, fearing that the condition of the afflicted passenger would worsen, or that the person would even die, and that she would then be morally responsible. In the same vein, she often had intrusive 
Targeting Catholic Rituals as Symptoms of Obsessive Compulsive Disorder:

A Cognitive-Behavioral and Psychodynamic, Assimilative Integrationist Approach

H.A. Garcia

Pragmatic Case Studies in Psychotherapy, http://pcsp.libraries.rutgers.edu

Volume 4, Module 2, Article 1, pp. 1-38, 05-12-08 [copyright by author]

thoughts about her younger brother dying from illness or getting into a fatal car accident. Consequently, she would cross herself and pray ritualistically when the thoughts randomly arrived and in response to antecedents such as her brother catching a cold, or when he left the house with his friends on weekends. These fears sank roots deeply into her sense of self, with her fearing that if she failed to avert harm this meant she was a selfish, uncaring, and even evil person.

Another example that proved central to her functioning arose during romantic encounters with her boyfriend. Rather than being able to live in the moment or immerse in the flow of experience, the encounters were punctuated by intrusions of guilt and ritualizing. While kissing her boyfriend, for example, she was often compelled to secretly cross herself behind her back, or sneak in looks up to the sky at moments in which she was sure he would not open his eyes. When these rituals were unsuccessful at ameliorating the feeling of guilt, she would excuse herself to the bathroom where she proceeded to kneel, pray, and cross herself compulsively. The more sexual the encounters became, the more intensely she experienced guilt, and in turn the more frequent and intense the ritualizing. The fear underlying these rituals was that if she failed to perform them, she was "going against God and Jesus" and was therefore "a bad person," although these fears did not coincide with her stated religious convictions. Specifically, she did not believe that pre-marital intercourse itself was a sin, although she maintained her virginity because, as she reported, she felt she wanted for wait for either marriage or a long term and deeply committed relationship, a type of relationship that she had not yet experienced.

Bridget also reported crossing herself secretly (e.g., in her coat pocket) when someone used blasphemous language or criticized religion, although she felt these expressions were normal and that hearing or verbalizing them were not serious violations of her religious canon. In fact, she reported that she often agreed with some of the criticisms she heard as part of the course of her liberal education at the University. She further stated that she critically evaluated the tenets of Catholic teachings herself and that she had her own criticisms about scripture, notions of God, and religious fundamentalism.

Bridget's symptoms had slowly but progressively worsened since the death of her father and have waxed and waned according to her stress levels. She reported that during the summer months, when not pressured by the demands of school, her symptoms notably dissipated. Her symptoms exacerbated in the weeks before seeking treatment, which, as with the initial onset of the disorder, coincided with the death of a family member-her godmother in this case.

Despite her suffering, Bridget was earning good marks in her full time study, held a job, and in the main her social functioning was adequate. Bridget was aware of her need for connection with others, and because she was outgoing and warm, she had been more than often able to elicit support. She described having a large network of mutually supportive friendships, and she reported being well liked by her peers, family, and professors. 


\section{Mental Status at the Beginning of Therapy}

Bridget was alert and fully oriented. Her affect was appropriate to context and her reported mood euthymic. Her speech was rapid and pressured, and at times mildly circumstantial, but on the whole organized, fluent, and at a normal volume. Her thoughts were logical and coherent, with no loosening of associations or flight of ideas. Throughout the initial interview she avoided eye contact. She denied a history of head injury or substance abuse and reported no medical problems. Bridget came across as amicable and warm, and she often smiled, appropriately, when she wanted to convey connection. She denied current or past homicidal and suicidal ideation.

\section{Diagnosis}

The Anxiety Disorders Interview Schedule for the Diagnostic and Statistics ManualFourth Edition (Brown, Di Nardo, \& Barlow, 1994) and the DSM-IV TR (American Psychiatric Association, 2000) were used to establish psychiatric diagnosis. Although Bridget presented with depressive symptoms and met criteria for dysthymia, nearly all of Bridget's depressive ruminations were congruent with her mood and revolved around her obsessions.

As mood congruency is also a feature of the excessive worry characteristic of Generalized Anxiety Disorder (GAD), the next step was to differentiate Bridget's symptoms from GAD. At first glance Bridget appeared to worry excessively about real-life events, a discriminating feature of GAD among anxiety disorders. Specifically, she worried about sexual issues, such as whether the performance of sexual behaviors would constitute the surrender of her moral values. However, further inquiry revealed that her concerns were better characterized as obsessions. One reason was that Bridget would perform the rituals described above in order to relieve the stress associated with her thoughts. Another was that her thoughts were focused around the more deeply rooted, less reality-based core beliefs typical of Obsessive-Compulsive Disorder, such as the irrational belief that one is immoral or wicked. Finally, her thoughts fell neatly within several of the cognitive domains outlined by the Obsessive Compulsive Cognitions Working Group (1997), an international collection of researchers who identified five core belief domains related to OCD. In summary, these included:

1) Inflated responsibility — an excessive appraisal of responsibility for intrusive thoughts and their imagined consequences

2) Thought-action fusion/overimportance of thoughts - the belief that thoughts are the moral equivalent to actions, or that simply having a thought means the thought itself is important and meaningful.

3) Belief in the importance of controlling one's thoughts - the belief that one can and should have complete control over one's thoughts

4) Overestimation of threat - an overestimation of the probability and cost of an aversive event 
5) Intolerance of uncertainty - the cautious, deliberative tendency seen in OCD [individuals] with regard to decision making that at times can result in excessive assurance-seeking.

Since Bridget did not indicate a concern about having or contracting a serious disease, no diagnoses of Specific Phobia of Illness or Hypochondrias were warranted. Because when referring to her obsessions she would frequently give qualifications such as, "But I know this isn't true,” indicating intact reality testing, no diagnosis of Psychotic Disorder or Chronic Psychotic Disorder was given.

Bridget did not meet the criteria for Obsessive-Compulsive Personality Disorder, primarily because her clinical presentation was characterized by obsessions and compulsions, rather than by a preoccupation with orderliness, control, or perfectionism. For this reason, and the reasons listed above, a primary diagnosis of Obsessive- Compulsive Disorder was given.

Since Bridget's depressive symptoms were characterized by a chronic and less severe course, rather than a severe course marked by discrete episodes, no diagnosis of Major Depressive Disorder was given. No diagnosis of a Substance-Induced Mood Disorder was given because Bridget reported minimal use of alcohol and no history of recreational drug use.

Although Bridget occasionally worried about her health, there was no evidence of a medical disorder. For this reason, the diagnosis of a Mood Disorder due to a General Medical Condition was not justified. For this reason, and the reasons listed above, Dysthymic Disorder was the secondary diagnosis given.

In sum, based on the above, Bridget was given the following formal diagnosis:

Axis I: Obsessive Compulsive disorder; Dysthymic Disorder

Axis II: None

Axis III: None

Axis IV: Problems related to the social environment

Axis V: 60

\section{Quantitative Assessment}

A variety of quantitative, self-report questionnaires, focusing on anxiety-related symptoms, were administered to Bridget at intake. The results are presented in Table 1 (see end of article below for all the tables), with scores that were at or above a clinical threshold indicated. Overall, the scores are consistent with the clinical results described above in the qualitative assessment and diagnosis sections. Specifically, the scores indicate that, compared with normed populations, at intake Bridget showed clinical levels of obsessive-compulsive symptoms (scale 2), depression (scale 3), worry (scale 5), and anxiety (scale 6); but non-clinical 
Targeting Catholic Rituals as Symptoms of Obsessive Compulsive Disorder:

A Cognitive-Behavioral and Psychodynamic, Assimilative Integrationist Approach

H.A. Garcia

Pragmatic Case Studies in Psychotherapy, http://pcsp.libraries.rutgers.edu

Volume 4, Module 2, Article 1, pp. 1-38, 05-12-08 [copyright by author]

levels of phobic attacks (scale 1), mobility problems (scale 4), post-traumatic stress syndrome (scale 7), and social avoidance (scale 8). (Note that because, in line with the above diagnosis, the focus of the therapy was on obsessive-compulsive problems and depression, only scales 2 and 3 [the YBOCS and the BDI] were re-administered at the end of the treatment to measure change.)

\section{Strengths}

Bridget also demonstrated a number of strengths, most notably of which was her connection to her large, closely knit and supportive family. She often described how her family provided to her a sense of closeness and identity. Also, as a person she was charismatic and likeable, and as a consequence she had a large network of friends who were also supportive. Adding to this, Bridget came across as both intelligent and hard-working. This helped her to conceptually grasp the material covered in treatment, to be adept at applying what she learned, and to be motivated to complete all the prescribed exercises throughout the course of treatment in a thorough and thoughtful manner.

\section{FORMULATION AND TREATMENT PLAN}

Bridget's OCD diagnosis met the clinical criteria for an empirically supported treatment protocol. Towards this end I used McGinn \& Sanderson's Treatment of Obsessive-Compulsive Disorder (1999) treatment manual, which includes provisions for methods outlined in the Guiding Conception section above. Following the manual, I employed a treatment plan that featured 15 to 25 sessions of CBT. Based on the preponderance of empirical support for the effectiveness of CBT in the treatment of OCD, this manual details cognitive restructuring and exposure and response-prevention (ERP) as treatment strategies. Note that one rationale for including a cognitive component is that cognitive distortions (Burns, 1989) help maintain OCD symptoms, such as "Labeling and Mislabeling” (e.g., "I'm a bad, selfish person if I don't cross myself when ambulances drive by"), and “All-or-Nothing Thinking," (e.g., "If I don't feel guilty about every injustice or malady in the world, I'm a bad person"). Also, secondary beliefs can underlie the symptoms mentioned above, such as, "I am a bad, evil, person for having intrusive thoughts of poisoning my customers.”

Another assumption, related more directly to ERP, is that avoidance maintains OCD symptoms, and ultimately the disorder itself, by not allowing the disconfirmation of a patient's irrational beliefs. Consider Bridget's checking behaviors as a form of avoidance. By checking stoves and solvent containers, she was avoiding the feelings of dread associated with her irrational feared consequence. This in turn prevented the disconfirmation of those fears-e.g., of burning the house down or poisoning her customers. E \&RP was to allow their disconfirmation essentially by demonstrating to Bridget that her feared catastrophes would not be realized even though no rituals were performed to prevent them. In the process it was assumed that she would habituate to the fear generated by not performing the ritual. Her ruminative praying held the same function as checking in this case.

The plans for the few first sessions were education on diagnosis and the cognitive model, as well as instruction in cognitive restructuring. Regimenting Bridget's praying to a reasonable, 
mutually decided duration and time of day was a goal of this portion of treatment. Relaxation training was next planned to raise her symptom threshold - i.e., to reduce her overall levels of stress below levels at which they are likely to trigger or have a marked influence on the intensity of her symptoms. Cognitive restructuring was to follow relaxation, focusing on Bridget's OCD and depressive cognitions. After five to six sessions, graded exposure and response prevention were to be performed.

\section{Phase 2}

What I had learned in assessing Bridget strongly suggested that the loss of her father in early adolescence and the corresponding development of her OCD had laid the groundwork for a defensive style characterized by displacement and denial. The void left by her father's death and her inability to sufficiently mourn his passing influenced her to seek boyfriends who would ultimately fail to fill that empty space, a task she had seemingly, unconsciously assigned to them. From these relationships she expected to gain a sense of identity and self esteem and this expectation often took the form of excessive reassurance seeking. These demands placed strain on Bridget's relationships and contributed to several breakups. The emptiness of her father's absence was reflected in the extent to which she seemed to be devoured by her obsessive rumination about the breakups. This cycle caused a great deal of distress and frustration, and seemed to erode her very sense of security in the world. Further, the breakups in particular triggered the deep-rooted guilt she had experienced since childhood about the passing of her father.

\section{COURSE OF THERAPY}

\section{Phase 1}

\section{$\underline{\text { Sessions 1-4 }}$}

Establishing a therapeutic relationship. At the beginning of therapy, Bridget was highly motivated for treatment, was psychologically minded, was friendly and likeable, and was eager to please the therapist by working hard on therapy tasks and assignments. These characteristics created the general conditions for the development of a strong, positive working relationship between Bridget and me throughout the therapy. On the other hand, these characteristics at times seemed to have a driven quality, raising clinical issues, as described below in the section on "over-compliance."

Relaxation. The first four sessions were focused on educating Bridget about OCD and the CBT model, as well as on teaching her relaxation and stress management skills. The CBT model was explained basically by describing to Bridget the manner in which distorted thinking patterns can result in anxiety, and the function of cognitive restructuring in correcting those distortions. The rationale for exposure \& response prevention (E\&PP) was also explained, as outlined above, by describing how avoidance prevents the disconfirmation of irrational beliefs, and how exposure is thus designed to allow their disconfirmation and ultimately to the reduction in her symptoms. 
Targeting Catholic Rituals as Symptoms of Obsessive Compulsive Disorder:

A Cognitive-Behavioral and Psychodynamic, Assimilative Integrationist Approach

H.A. Garcia

Pragmatic Case Studies in Psychotherapy, http://pcsp.libraries.rutgers.edu

Volume 4, Module 2, Article 1, pp. 1-38, 05-12-08 [copyright by author]

Autogenic Training (Schultz \& Luthe, 1959) was the first method taught for relaxation, which involves focused attention on various points throughout the body using relaxing imagery and sensations (e.g., imagine your arms as being warm and heavy). As part of this training, I gave instruction in diaphragmatic breathing to Bridget as well. Although she sat compliantly through the exercise and listened to an audiotape of the session for homework, she reported that this method ultimately made her more tense and anxious. She said that as soon as she attempted to focus her attention on a particular body part, her mind wandered and she then was barraged more heavily by intrusive thoughts. Further investigation of Bridget's paradoxical response to the exercises indicated that when a thought occurred to her outside the context of the exercise, she attempted to force that thought out of awareness. As these attempts failed, she experienced irritation and anxiety. This reaction is consonant with research showing that such thought suppression is an important factor in the experience of OCD symptoms (for a review see Purdon, 2004).

Faced with this impasse, we switched to Progressive Muscle Relaxation (PMR) (Jacobson, 1938) as our default relaxation exercise with the rationale that the efficacy of PMR was less contingent on cognitive processes and therefore less subject to intrusive thoughts. As the goal of relaxation training was to remove as much as possible the contribution of stress to the manifestation of symptoms, rather than as a triage response to acute stress or anxiety, in addition to prescribing regular sessions of PMR as homework we created a list of stress-reducing activities she could regularly perform at home. For example, these included taking hot baths, exercise, reading outside of material assigned at school, and listening to music. She was instructed to perform at least one of these behaviors for one hour, at least four times per week, and PMR for ten minutes, at least three times per week.

Praying. Bridget reported praying many times during the day, sometimes in direct response to obsessions, at other times without a noticeable trigger. While unable to notice specific unwanted thoughts at such times, she reported feeling as though the praying behaviors were set within a complex of intermittent bouts of anxiety and were therefore "anxiety-driven." This type of "anxious praying" was particularly reminiscent of the reassurance-seeking that is so typical of OCD and seemed to take a perseverative rhythm, e.g., to "help me keep friends -- my boyfriend -- do well in school -- protect my mom, my brother, my customers at work, my friends...” Because praying is a practically universal feature of religion with the potential for fostering emotional well-being, not to mention an intrinsic human right according to values of Western society, the wholesale extinguishing of praying - as is the goal with most other targeted rituals in OCD treatment-simply was not an ethical nor desirable strategy in this case. Accordingly, at this time we also proceeded to relegate Bridget's praying behaviors to specified amounts and periods during the day. Again, here I am differentiating between (a) the "compulsive praying" that was short in duration and specifically in response to a perceptible obsession, such as praying in response to an ambulance siren (which would be targeted later during ERP), versus (b) anxious praying that was longer in duration and not directly in response to a perceptible obsession, yet was used instrumentally to reduce an undercurrent of anxious tension. 
Targeting Catholic Rituals as Symptoms of Obsessive Compulsive Disorder:

A Cognitive-Behavioral and Psychodynamic, Assimilative Integrationist Approach

H.A. Garcia

Pragmatic Case Studies in Psychotherapy, http://pcsp.libraries.rutgers.edu

Volume 4, Module 2, Article 1, pp. 1-38, 05-12-08 [copyright by author]

Because there appeared to be an element of avoidance to the "anxious type" of praying, we spent a good amount of time discussing the different motivations for praying in an attempt to differentiate healthy versus pathological praying. We identified common reasons for praying, which we viewed as "healthy," such as: for worship, for divine inspiration, for spiritual fulfillment, for a closer relationship with God, to give thanks, to gain wisdom, to express frustration or pain, or to seek guidance. This we differentiated from the anxious type of praying. The qualities of the two types were by no means completely distinct. Clearly under normal circumstances anxiety reduction is a common aspect of praying and an aspect of Bridget's praying when she was praying for the healthy reasons just described. But most of the time the motivation for Bridget's praying was strongly in the direction of anxiety-reduction and in response to intrusive thoughts. The task then was to separate those instances in which she was mostly praying for worship ("healthy” praying), and mostly praying to reduce anxiety ("unhealthy" praying). This was done both to make her more cognizant of unhealthy OCDdriven praying and to suggest that she focus on "healthy praying" during certain specified times. Further, as unhealthy praying fit the model of symptom maintenance in OCD - the drive to perform behaviors to avoid anxiety, preventing disconfirmation of fears - I saw the prescribing of healthy praying as taking momentum away from the unhealthy praying, even though the unhealthy praying was not always directly in response to an intrusive thought. I further believed that there were cognitive processes such as unwanted thoughts or emotions outside of Bridget's awareness to which she may have been responding by a ritualized praying. =

Bridget agreed that fifteen minutes during the day and before bed was an acceptable amount of healthy praying. She initially had a difficult time sticking to this regimen, reporting that her days involved trying willfully to resist unhealthy praying and being able to do so for a short time, but repeatedly breaking the restraint with flurries of intensive praying that seemed more frenzied than before treatment. We agreed to move forward with treatment with the anticipation of the gains made through other modules of treatment generalizing to this behavior.

Over-compliance. Coming across as friendly and charming, Bridget was an easily likable patient. She had a positive attitude toward therapy and was compliant, which made for a fairly efficient course of treatment. Before long, however, I felt that she was becoming over-compliant. My first inkling of this was very subtle, which was initially fed by nuances in her overall demeanor and non-verbal behaviors. When instructed to perform tasks, she sat intensely alert in a manner that demonstrated a willingness to comply with treatment with a fervor that seemed somewhat overstated, or at least it had grabbed my attention as a hypothesis to later weigh against more information.

I eventually viewed her strong motivation to comply as a target of treatment at the same time that it was an asset. First, the desire to abide by rules gave her an incentive to do homework exercises as well as to participate actively in session. This took place in a notably meticulous fashion, as opposed to avoiding the work. Her compliance was also a target insomuch as it stemmed from a rigid investment in being morally irreproachable. The determination of what we regarded as rigid came also from Bridget's own self assessment — upon exploration, she stated that her striving to be morally right in her actions and thoughts were the cause of stress and anxiety. Further, acting in an excessively acquiescent manner served as avoidance for Bridget - 
Targeting Catholic Rituals as Symptoms of Obsessive Compulsive Disorder:

A Cognitive-Behavioral and Psychodynamic, Assimilative Integrationist Approach

H.A. Garcia

Pragmatic Case Studies in Psychotherapy, http://pcsp.libraries.rutgers.edu

Volume 4, Module 2, Article 1, pp. 1-38, 05-12-08 [copyright by author]

by doing so she avoided feeling as though she were morally vapid or evil, because moral uprightness for her involved abiding strictly by rules and principles and by perceived expectations of her. One example was that with her friends she often took great pains to sublimate her thoughts, words and behavior to those that she felt were expected of her, sometimes clearly at the expense of her true feelings - in her words, she put forth an inordinate amount of effort to be "a good girl" and also to be "perfect," but good by standards held by her alone. Another piece of information was the zeal with which she took to therapeutic tasks themselves. It seemed clear that she took to tasks in a way reminiscent of her more overt ritualizing. The manner was hurried and somewhat frantic, as someone with a feverish thirst rushing to alleviate her discomfort with a drink of water. As such, the style in which she performed the work itself became another point of intervention.

\section{Sessions 5-10: Cognitive Restructuring}

The next stage of treatment (sessions 5-10) consisted of cognitive restructuring. Cognitive distortions were readily pinpointed in this phase, such as those mentioned above. Other thoughts falling within the domain of distortions, such as "Overgeneralization," "Personalization" or "Disqualifying the Positive" (Burns, 1989) were: "If I hear blasphemy and don't cross myself, this means I'm a bad person," and "If I don't cross myself and pray when my brother goes out at night, that means I wish him harm or that I'm a bad, evil, selfish person.” Catastrophic thoughts were identified such as, "If I don't check the stove repeatedly, the house will burn down and my family will die.”

When this phase began, Bridget's automatic thoughts and rational responses were both rambling and circumstantial in a manner characteristic of her speech. For this reason the goal of initial sessions was to bring the restructuring itself into focus and to develop Bridget's skills at identifying the automatic thoughts. I first saw the rambling nature of Bridget's work specifically the jumping from one possible automatic thought to another - as most likely a function of avoidance, as the skipping repeatedly across the surface without ever venturing down to any depth of experience. Though on the surface she appeared to be engaged in treatment, she was avoiding anxiety-producing stimuli by lingering for only moments on one topic before redirecting her focus to another.

I soon discovered that not only was avoidance occurring on this level, but that Bridget began using the cognitive facet of treatment in a ritualistic manner, such as by silently repeating the cognitive distortion underlying a particular obsession, i.e., "It's just Magnification, it’s just Magnification.” She also began ritualizing the rational responses-in response to selfdeprecating cognitions, she would repeat over and over, e.g., "People usually give me positive feedback, so while I'm not perfect, I'm a good person.” This sometimes went on for hours.

Another issue that arose during the cognitive component of treatment was that the writing of restructured thoughts onto worksheets became excessive, sometimes requiring the attachment of additional pages - the most common length normally being only a few sentences per automatic thought. She reported the reason for this was that she did not want to miss a possible rational response to her distorted cognitions, and that if she did she would feel guilty, as if she 
were not fully doing what was expected of her. Again, this was conspicuously reminiscent of her performing religious rituals to prevent anxiety and, on the cognitive level, the moral condemnation of her character. For this she was encouraged to intentionally not include some of her rational responses, and to intentionally be more flippant about her performance. In subsequent sessions her rational responses were much briefer, usually consisting of three or four succinct sentences per irrational fear. Thus, somewhat ironically, she complied with my instructions to not be so rigidly compliant. However, as rituals are imbedded within larger systems of meaning, I also decided to devote a portion of several sessions to explore the connotations of doing what was expected of her with regard to her self image, her perceived desirability, her perceived ability to secure intimacy, and her beliefs about the repercussions of not doing so. I chose to pursue this exploration in a conversational style, because Bridget had frequently been responding to the structured tasks of the cognitive therapy with a ritualizing behavior style.

During this phase of treatment, however, Bridget appeared to gain slightly more control of her praying behaviors, although she reported still praying outside the specified times in response to her anxiety. It was not until several sessions of ERP had been conducted that she began to limit her praying to the specified times.

Shortly after it was discovered that she was ritualizing the cognitive restructuring process, ERP was initiated with instruction to hold off on the cognitive facet of treatment until the ritualizing subsided. The rationale for this was explained. This involved sharing the hypothesis that topic-skipping can serve as a means of avoidance, and reiterating the explanation that ritualizing can also serve as a form of avoidance, in line with cognitive-behavioral formulations of OCD.

\section{Sessions 11-27: Exposure \& Response Prevention (ERP)}

In session 11, a fear and avoidance hierarchy was then constructed. Most of her preoccupations and the attendant rituals were of a sexual nature, and she reported that her strongest desire for treatment was to deal with her compulsions surrounding sexual thoughts and behaviors. Although initially all of the sexual items of the hierarchy were imaginal, Bridget reported that if she had lived closer to her boyfriend (who lived out of state) she would have wanted to perform the exercises with him in vivo. Most of the other items fell within the cognitive domain of inflated responsibility, such as the unrealistic feeling that she was responsible for the well-being of ambulance riders, her brother, and diners at her restaurant. Bridget rated each item on the hierarchy in terms of both her fear of it and her urge to avoid it. In making these ratings, she used a "Subjective Units of Distress" (SUDS) scale, ranging from 0, no fear or avoidance, to 8 , the highest level imaginable. Table 2 shows the results of these ratings in the first session and in session 27, the end of Phase 1.

The remainder of this stage of treatment (sessions 12-26) involved ERP. All of the imaginal exposure sessions were recorded on audiotape. For her issues with ambulance sirens, Bridget imagined in great detail the circumstances in which she normally ritualized when hearing them. This involved mental imagery such as: driving down the road in her car; the place where 
Targeting Catholic Rituals as Symptoms of Obsessive Compulsive Disorder:

A Cognitive-Behavioral and Psychodynamic, Assimilative Integrationist Approach

H.A. Garcia

Pragmatic Case Studies in Psychotherapy, http://pcsp.libraries.rutgers.edu

Volume 4, Module 2, Article 1, pp. 1-38, 05-12-08 [copyright by author]

she normally performed this particular ritual; catastrophic images about the state of the afflicted passenger inside; and how the accident leading to the patient's injuries occurred. To aid the visualization I downloaded siren sounds from the Internet, played a recording of them in session, and guided Bridget in abstaining from ritualizing. A recording of the session, including the background of ambulance sirens, was given to Bridget with instructions to listen to the tape several times before the next session and to avoid ritualizing while doing so. She responded quickly to this facet of treatment-the crossing and praying behaviors extinguished completely within two sessions (12-14), and the associated obsessions significantly diminished.

Similar steps were taken to curb her ritualizing upon hearing "blasphemous" language voiced by her friends. To provide us with some sort of starting point we began with the expressions that commonly incited her ritualizing. This consisted of expressions like "Goddamn" or "Jesus Christ” or even academic criticisms argued by students or professors in school who critiqued certain Biblical concepts such as creationism, Immaculate Conception, and sin. Initially, I began by verbalizing these very things to her in session and preparing a tape for later exposure. After this session (session 15) and one week of taped exposure homework, she commented that she was still ritualizing with the same intensity. It turned out that the session content failed to rouse much anxiety. This, she reported, was because my voicing criticism to intentionally produce anxiety lacked a certain realistic conviction she believed necessary to make her anxious.

My objective was to then arouse more anxiety — as mentioned above, a critical element of exposure that was explained to Bridget at the outset of treatment - by making the statements, so to speak, more blasphemous. Though she at first was understandably very bashful and anxious, she soon immersed herself in this task by brainstorming blasphemous thoughts at the instruction to imagine the worst thing about God or Jesus or the Bible that someone either had or could ever say to her. She came up with a mass of rhetoric such as: "Priests are all faggots waiting to screw little boys," "the Virgin Mary was just a whore that Joseph screwed to make Jesus, her illegitimate son,” or, “Jesus was just some troublemaker that the Romans deservedly put to death." Verbalizations such as these, particularly if they contained coarse language (for the record, language reflecting views to which I do not personally subscribe), consistently produced sevens and eights on the SUDS scale. I added to this material and asked her to rate her anxiety per verbalization, and based on those ratings I got more of an idea of the types of verbalizations that triggered her OCD with more intensity. Based on these data, I improvised a 45-minute exposure session of the basest, most sacrilegious spewing I could muster, which I taped for homework exposure.

Even as a non-Christian, I felt horrible saying these things outright, especially to this sweet and likable young woman, whom I could see wincing in the reclining chair in my office and fighting off the urge to make the sign of the cross. Subjectively, it was a bizarre experience, perhaps the strangest I have had as a therapist. The content was so over the top and seemingly more appropriate for lines of a horror movie script - the one where the spirits inside a possessed girl force her to hiss out curses and spit. Yet this discourse was something that would ultimately ease her suffering, which I also knew and relied upon to help me perform in my role. The irony was something to remember. To my relief Bridget had a sense of humor about the whole 
Targeting Catholic Rituals as Symptoms of Obsessive Compulsive Disorder:

A Cognitive-Behavioral and Psychodynamic, Assimilative Integrationist Approach

H.A. Garcia

Pragmatic Case Studies in Psychotherapy, http://pcsp.libraries.rutgers.edu

Volume 4, Module 2, Article 1, pp. 1-38, 05-12-08 [copyright by author]

situation and was able to perform the homework exercises as prescribed. Within one week of the more intensive exposure (session 16) she was no longer ritualizing to these stimuli and reported that the anxiety roused by blasphemy of the everyday variety, while still existing in traces, had diminished to the point that she hardly noticed its presence.

Bridget's fear of her brother dying was addressed similarly. She reported that whenever her brother, Shannon, left the house with his friends on the weekends, she experienced intrusive thoughts of him getting into a fatal car accident. Subsequently, she forced those thoughts out of awareness or attempted to neutralize them with obsessive praying and crossing or by checking the news for accounts of fatal car crashes. She also engaged in thought suppression and ritualizing when Shannon showed signs of mild illness (e.g., flu or cold), fearing that the symptoms would worsen and that he would die. By the time Bridget sought treatment, she was ritualizing in response to Shannon coughing, sneezing, or even blowing his nose. Underlying these rituals was the irrational belief that she could ritualistically prevent his death.

Here I chose to start with imaginal exposure for a number of reasons. First, the intrusions generated a great deal of anxiety, which is understandable considering that the onset of Bridget's symptoms involved rituals aimed at curing her father's illness and preventing his death. Consequently ritualizing to protect Shannon held a great deal of emotional valence for Bridget and was therefore quite intense and prolonged. As opposed to merely instructing her to not ritualize (response prevention) when he brother left the house or became ill (exposure), conducting imaginal exposure in my office would allow me to directly monitor the procedure to ensure it was conducted in a thorough fashion-i.e., that response prevention was carried out fully, and that subtle avoidance was not occurring outside of her awareness. Second, Shannon had a girlfriend who lived in another city and he often stayed with her on the weekends, thus limiting the opportunities for Bridget to self-administer the treatment in vivo. Third, imaginal exposure gave me the ability to imaginally create idiosyncratic situations in my office that would normally be unfeasible in vivo, for example, waiting for Shannon to get ill. In this case Bridget reported that she wanted to keep her treatment private, which precluded asking her brother to facilitate treatment by feigning illness by coughing and sneezing, or, say, by going out with his friends every night for a specified time.

We began by creating a detailed scenario of the progression of Shannon's illness (session 17). We discussed what would comprise the scenario beforehand, and I instructed Bridget to narrate. The main points of the scenario, which were elaborated in detail for 45 minutes, were as follows. Shannon began complaining of fatigue, headaches, and muscle pain. As symptoms worsened he began coughing, sneezing, and then vomiting. Eventually he caught pneumonia and was taken to the hospital. After being put on life support he eventually died. The same level of detail was created for her car-crash obsessions. Bridget initially showed a great deal of anxiety performing this segment of ERP. Her breathing visibly become more rapid and she shifted around in her chair. In addition to this, she avoided narrating the scene by hurrying through the narrative and omitting anxiety-producing detail. It took several redirections to produce a scene with sufficiently vivid imagery. 
Targeting Catholic Rituals as Symptoms of Obsessive Compulsive Disorder:

A Cognitive-Behavioral and Psychodynamic, Assimilative Integrationist Approach

H.A. Garcia

Pragmatic Case Studies in Psychotherapy, http://pcsp.libraries.rutgers.edu

Volume 4, Module 2, Article 1, pp. 1-38, 05-12-08 [copyright by author]

When Bridget finally was able to create a complete image, we recorded an audiotape and assigned the exposure as homework, as with the other items. One week of taped exposure reduced her symptoms by about half of their original time and intensity (as measured by the YBOCS, her initial obsessions score went from 8 to 5, and her initial compulsions score, from 10 to 4). One obstacle to this hierarchical item was that Bridget's brother happened to be home for the week she was self-administering the taped exposure. While she reported gradual reductions in her ritualizing in response to the tape, she continued to cross herself and pray when Shannon left the house or coughed, and in response to intrusive, catastrophic thoughts without discernible antecedents. She stated that she felt this was an exercise of her religious belief, and she was attempting to pray and cross for that reason only. However, by the end of the week she began crossing repeatedly (and praying excessively) in response to these in vivo stimuli, and the reductions in her ritualizing to the taped exposure remained in stasis. When she came to session I suggested that for the following week she refrain from praying and crossing altogether in response to the foregoing stimuli. She agreed to try this for the duration of CBT treatment. Though she reported difficulties for the first few days, her ritualizing was close to zero by the end of the subsequent week (session 18).

Relative to her response to subsequent items, her fears of not checking were somewhat recalcitrant, or at least they did not respond to the ERP by the means in which I first administered it. Initially I was unsure how to structure the exposure. I had considered instructing Bridget to administer her own ERP by simply refraining from checking in response to her fears. However, given the level of anxiety these fears created and her difficulties in self-administering ERP on the previous hierarchical item, I chose to start with imaginal exposure to her feared catastrophe.

The crux of ERP is to expose the person to the avoided stimuli that is the cause of his or her catastrophic fears and to prevent the corresponding compulsion. The basic rationale for this is somewhat straightforward-once the catastrophic fears are not realized, even though no rituals were performed, a re-appraisal process takes place in which the feared stimuli are no longer regarded as dangerous and the rituals are no longer seen as necessary.

However, in this case the feared stimulus was, for instance, leaving the gas stove on, which has the potential for realistic danger. Upon seeking consultation on this issue from two different supervisors, I received conflicting responses. The first supervisor said that if you expose an individual imaginally to his or her catastrophic fear, a process takes place whereby in explicitly verbalizing the imagined catastrophe, the person begins to internalize the inherent flaw in the reasoning underlying his or her fears. This results in the person cognitively distancing him or herself from the irrational fear, e.g., "Now that I say this aloud I see how truly unlikely this is to actually occur" or, perhaps more explicitly, "Now that I say this aloud, I see how unlikely it would be that I would actually leave the stove on, and how exaggerated and incredible an outcome are my visions of a house engulfed in flames."

In contrast, the second supervisor argued that exposing someone to the fear of a legitimate catastrophe, specifically the consequences of leaving the stove on, could desensitize 
Targeting Catholic Rituals as Symptoms of Obsessive Compulsive Disorder:

A Cognitive-Behavioral and Psychodynamic, Assimilative Integrationist Approach

H.A. Garcia

Pragmatic Case Studies in Psychotherapy, http://pcsp.libraries.rutgers.edu

Volume 4, Module 2, Article 1, pp. 1-38, 05-12-08 [copyright by author]

the client to leaving on stoves and thereby create a higher probability that she could set up a situation leading to the burning of her house with possible severe harm to her family.

All things considered, I decided to go through with the exposure. Exaggerated scenarios were imagined in which her failing to check led to catastrophic ends (session 19). For this she was encouraged to take liberties in imagining her worst nightmare coming true. For example, she would not check the solvent containers, leading to an entire restaurant of patrons green of skin, with mouths foaming and clutching their throats before collapsing face-first into the plates she brought out to them; and she would not check the stove leading a house engulfed in flames, her parents on fire, and the flames leaping from her rooftop to surrounding houses, eventually resulting in an entire block of incinerated homes. While the impact of these procedures for the stove-checking were minimal, they had a substantial effect on reducing Bridget's anxiety and her checking with regard to the customer-poisoning obsession - perhaps as a function of the impossibility of poisoning the meals by not solvent-checking as opposed to the conceivability of an accident occurring by failing to turn off the stove.

After reporting the impasse to my supervisor, we decided to switch to a purely behavioral approach. By each lock (i.e., both front and back doors of her home) and by the stove Bridget placed a writing pad in which she would log the number of times per day that she checked. Similarly, Bridget documented the numbers of times she checked the solvent containers, though privately on the pad on which she took orders. We then set a schedule by which Bridget was to eliminate the checking behaviors in a graded fashion. Because she reported later that she found the logging itself aversive, we also mutually agreed upon contingencies to apply to checking.

We decided that she would only watch TV if she successfully reached her target for the day. Relatively rapid reductions in stove and lock checking behaviors (sessions 20-21) to normal levels were seen with this approach. Bridget reported that in manually documenting the high number of times she checked, the irrationality of her belief that she had failed to check the first time became palpable enough to provide the certainty to stop checking. Not only did this involve the disconfirmation of her irrational fears, but also it produced the cognitive distance as described by my supervisor above. Positive gains were also made with solvent-checking, which reduced to zero at the end of session 21.

\section{Sessions 22-27: Symptoms Related to Sexual Behaviors}

The remaining sessions were devoted to treating symptoms related to her sexual impulses. The avoidance of sexual thoughts before treatment prevented Bridget from holding such thoughts in mind long enough to consider which specific behaviors were in accord with her own principles. As such, a thorough discussion of her values pertaining to sexual matters took place, covering an entire session. Rather than being an experience of self discovery, the process seemed more like the verbalization of beliefs and values that already existed "under the radar," but thus far were avoided. She reported that performing and receiving oral sex were acceptable to her and that she had engaged in these behaviors with her current boyfriend, albeit while ritualizing. As mentioned above, she also reported that she had not had intercourse and that having intercourse before marriage was contrary to her current values and wishes. However, she 
Targeting Catholic Rituals as Symptoms of Obsessive Compulsive Disorder:

A Cognitive-Behavioral and Psychodynamic, Assimilative Integrationist Approach

H.A. Garcia

Pragmatic Case Studies in Psychotherapy, http://pcsp.libraries.rutgers.edu

Volume 4, Module 2, Article 1, pp. 1-38, 05-12-08 [copyright by author]

reported that thoughts of having intercourse sometime in the future generated a great deal of anxiety and was evocative of her obsessional anxieties, rather than normal jitters about having sex for the first time. For this reason I suggested that imaginal exposure to this behavior be performed as well. She agreed and this imagery was incorporated into the exposure regimen.

Bridget also reported that when discussing sexual issues and behaviors with her friends she was always the least explicit, communicating through innuendo and avoiding the use of specific terminology. A careful discussion of specifically what terms she would use during exposure took place because, rarely having used such words in the past, she was at first unsure how she would actually describe the scenarios.

Because Bridget reported feeling uncomfortable going into great detail about the mechanics of the specific behaviors, as was done with other exposure exercises to create a sense of realism, particularly in the presence of a young, male therapist - e.g., "Now I am doing this behavior with this body part to that body part of his and his specific response is this" - she agreed to hold silently in imagination the scenario in detail upon leading the narration to a such a point as, for example, "Now I'm imagining performing oral sex." She agreed to do this to the best of her ability without avoidance, and to report when she was unable to hold the imagery in mind as a function of avoidance. I did my best to contain my sigh of relief when we finally agreed upon this. With all the expected anxieties of merely trying to function competently in my first case, I faced the anxiety of asking a young female patient to basically lead in pornographic detail an extended reel of sexual imagery. Although this tortured her very deeply, my recommendation as an authority on such matters was that not only was this required but that I had to listen while she described this and, in fact, redirect her to be more graphic if I felt she were to be too prudish in her descriptions (i.e., avoidance) of her and her boyfriend's performance in the bedroom. Aside from being much easier for me personally as the therapist, I also believed that the benefits of having Bridget go into additional detail verbally would be negligible, particularly when weighed against the benefits to the treatment alliance of demonstrating to her my respect for her personal values and boundaries. Further, I was well prepared to change my strategy if this was unsuccessful. We agreed to test the effectiveness of this approach and modify the imagery toward more explicit detail if sufficient anxiety was not generated or if the ritualizing continued.

We quickly found that sufficient anxiety was indeed generated for the exposure to work. As with the other exposure exercises, ritualizing was watched for and prevented in session. Bridget commented that during exposure she had felt the urge to cross herself. Although she abstained from crossing in an obvious manner - i.e., across her chest and forehead - she began lightly tapping her fingertips in a ritualistic fashion into the armrest of the recliner, sometimes tapping in the sign of the cross. This began in a manner barely registering within her awareness. So subtle was this that I almost failed to notice it myself. This was pointed out to her in session with the instruction to stop, which she was able to do successfully with only a few reminders across sessions.

Imaginal exposure substantially reduced Bridget's ritualizing, subjective anxiety, and cognitive avoidance surrounding her sexual fears. Further, this aspect of treatment generalized to 
Targeting Catholic Rituals as Symptoms of Obsessive Compulsive Disorder:

A Cognitive-Behavioral and Psychodynamic, Assimilative Integrationist Approach

H.A. Garcia

Pragmatic Case Studies in Psychotherapy, http://pcsp.libraries.rutgers.edu

Volume 4, Module 2, Article 1, pp. 1-38, 05-12-08 [copyright by author]

real life within the relationship she had with her boyfriend. During and after this facet of treatment she enthusiastically arranged travel to Florida where her boyfriend lived to test the gains made by imaginal exposure. She reported that while she initially experienced mild anxiety and the urge to ritualize, she was able to enjoy the behaviors she had performed in the past without ritualizing. The success of this facet of treatment went further. Prior to treatment Bridget so constrained her sexual impulses that she willfully withheld orgasm during sexual encounters. It was not the case that she was unable to achieve orgasm, as she perceptively noted - she was regularly able to achieve orgasm while masturbating. It was that she intentionally restrained her own sexual enjoyment for fear that if she allowed herself to climax with a man she would be "going against God," and therefore would be an "evil person.” As with many of the other beliefs, she firmly stated upon reflection that this was not her true view but her irrational fear. And over the course of several months she reported being able to climax during sexual encounters with her boyfriend on several occasions. This gain was made without the specific treatment focus on orgasm but through generalization of treatment to her regard and experience of sex more globally — that is, through restructuring distorted beliefs (i.e., "going against God," "I'm an evil person") across behaviors in the cognitive facet of treatment as well as ERP.

Overall, the CBT phase of treatment proved effective in significantly reducing Bridget's OCD symptoms. The details of the outcome of Phase 1 are presented in the Monitoring Therapy section below. However, Bridget's rapid and circumstantial style of speech was still present at the end of treatment, and this became one of the foci of Phase 2 of the therapy.

\section{Phase 2 (sessions 28 to 79): Integrating Psychodynamic Concepts and Strategies to Address Two Remaining Problems}

Note that because of the less structured nature of Phase 2, similar themes wove in and out across the sessions. For this reason, I present the material in this phase by theme rather than by chronological session.

\section{Transition to Phase 2}

As described above in the Guiding Conception section, Phase 2 of the therapy involved the assimilative integration into the CBT therapy of psychodynamic concepts, particularly those of transference, countertransference, and interpretive exploration of childhood history. These approaches ended up being directed primarily at two problems which remained after Phase 1 of the therapy, and which seemed to come from the same underlying processes that caused the obsessions and compulsions addressed in Phase 1. These problems were: (a) a tendency for Bridget to be attracted to high-status men who were ultimately unattainable, leading to eventual rejection; and (b) a rapid, pressured, and scattered style of speech, interfering with her ability to effectively communicate with not only me, but with important others in her life.

At the end of Phase 1, Bridget was still attending the university and stated she wished to continue treatment with me. She stated that she wanted to gain more insight into patterns within intimate relationships that seemed repetitive and counterproductive. She reported that in her relationships with men she often felt out of control and that at times she clung frantically to her 
Targeting Catholic Rituals as Symptoms of Obsessive Compulsive Disorder:

A Cognitive-Behavioral and Psychodynamic, Assimilative Integrationist Approach

H.A. Garcia

Pragmatic Case Studies in Psychotherapy, http://pcsp.libraries.rutgers.edu

Volume 4, Module 2, Article 1, pp. 1-38, 05-12-08 [copyright by author]

partners, particularly as the relationships ended. She cited two former relationships in which the breakups were marked by her inability to arrive at emotional closure, states of anxiety and discontent that in turn seemed to exacerbate her OCD symptoms. In both cases she struggled to accept the fact that her boyfriends broke up with her and ruminated about the implications of the breakups with regard to her self worth, e.g., "If my partners don't want me, then I have no value”.

\section{Bridget's Relationship with her Father as a "Hot” Issue}

As a means to facilitate the change from the structure of CBT to therapy that was more free-form and open-ended, I initially offered example topics for exploration. Among many were the qualities and patterns of past relationships with men, her current social network, and dynamics within her family of origin, including her relationship with her father and her experience of his early death. Her response to the last item stood apart. Hands waving in front of her, she hurriedly refused, insisting that she "already covered” her father's death in prior therapy, referring to a short stint in psychodynamic therapy in high school. The manner in which she waved this aside was obviously departing from her usual eager and psychologically-minded style. For a few weeks in the beginning of treatment she offhandedly repeated this sentiment when topics came up that were only indirectly related to her father. Of course the more she argued this position the more conspicuous the anxiety that the topic produced in Bridget became, and in turn the easier it became to view her dismissals as avoidance, rather than as reflecting her having already come to terms with the loss.

\section{Bridget’s Monologues and Pressured Speech}

The transition from CBT to less structure went smoothly, and Bridget soon found a rhythm for talking without a palpable format per se. In fact, the pressured and circumstantial style I occasionally noticed during CBT eventually took over and she soon began flitting energetically from topic to topic, scarcely taking a breath it seemed for the span of entire sessions. Over time what I expected would be discussions evolved into lengthy monologues. When I made interventions she would give me space to talk, sitting perkily up and attentive, but behind the eyes was always a gnawing impatience that seemed to experience my interventions as frustrating interruptions of her stream of speech. As soon as I finished speaking, she would release herself from her posture of obligatory politeness, which she held rigidly and with some degree of difficulty, to continue the flow pretty much full speed.

The pressured nature of her speech seemed to throttle forward most fervently while on the topic of her current boyfriend, Adam, a topic that began to comprise most of our time working in this new modality. The "monologues" therefore fell within a number of somewhat circumscribed domains. These included: the sexual choices that she made with Adam, such as what sexual behaviors they performed and what this meant for her identity as a virgin; his regard of her; and issues of self-esteem. She discovered that she tended to be attracted to men who were somewhat unattainable or out of reach, and imposing in either physical stature or social status. She reported that the previously unstated rationale for this was something like: such men could afford to be selective and that because they chose her this meant she was "high-quality." Adam 
Targeting Catholic Rituals as Symptoms of Obsessive Compulsive Disorder:

A Cognitive-Behavioral and Psychodynamic, Assimilative Integrationist Approach

H.A. Garcia

Pragmatic Case Studies in Psychotherapy, http://pcsp.libraries.rutgers.edu

Volume 4, Module 2, Article 1, pp. 1-38, 05-12-08 [copyright by author]

was a football star at his college in Florida, and his living in a distant state made him in a symbolic sense all the more inaccessible (and therefore more attractive) to her. Bridget was adept at identifying this and other similar examples of her thought process, and my feeling was that her prior training in cognitive restructuring was a facilitating factor.

During the course of treatment (approximately session 46) Bridget discovered that Adam cheated on her with his ex-girlfriend. This devastated Bridget. Subsequently, she broke up with him and used months and months of therapy processing the events leading up to the breakup. Though we explored other areas, Bridget appeared to be unusually fixated on this topic. A year later, broaching the topic continued to evoke an obsessive style which played out through entire sessions of streaming rumination. The intensity of the rumination did not attenuate over the course of a year, rather than gradually dissipating as one would expect with a pattern of normal grieving.

I mentioned Bridget's pressured speech to her several times. She reported that her friends had made similar observations. Each time I mentioned this she took note and in an acquiescent fashion - e.g., hands crossed on lap, better posture - slowed her speech to a normal level for the rest of session. However, by the next session she was back to "monologuing."

I tried asking her directly to slow her pace, explaining to her the importance I saw in delving into one topic and corresponding emotion at time. Basically, I explained how anxious avoidance could prevent her from processing the complex of emotions wrought by the breakup by never allowing her to fully experience a single emotion, such as sadness, humiliation, confusion, or perhaps anger and resentment. When this failed to result in normal speech, I struggled to re-conceptualize her style in order to make an appropriate intervention.

After rethinking hypomania as a secondary diagnosis, which I ruled out a second time because there were few if any affiliated symptoms, I began to consider secondary gain. Instead of raising the issue immediately, however, I instead focused more on the loss of the relationship with Adam. It was only months later (session 70) that I brought the issue to the fore, a choice of timing that in hindsight I would not have made (a point discussed in more detail below). When I finally nudged Bridget to consider the possible rewards she had wired into her ruminations (i.e., a functional analysis), she began the task with a great deal of determination. Her first discovery was that ruminating, for example about the ways in which Adam wounded her, was personally stimulating and made her seem more interesting to others. She illustrated how her friends gathered around her, relishing the dramatic spin she was able to create about the breakup. By describing her experience with great detail and emphasis she easily enlisted her friends in reproaching Adam. Her friends further responded by furnishing generous amounts of support and empathy. Bridget recalled that she learned this strategy for connecting at an early age, recounting that upon her father's death family and friends lavished her with attention. Another reward was that amongst her teenage peers losing her father imparted a certain status and admiration. Apart from attention-seeking, she recognized that she used her ruminative manner as a form of coping - the more she ruminated, the more she was able to elicit support from others, irrespective of whether her ruminations were in perfect accord with her inner state. Further, the 
Targeting Catholic Rituals as Symptoms of Obsessive Compulsive Disorder:

A Cognitive-Behavioral and Psychodynamic, Assimilative Integrationist Approach

H.A. Garcia

Pragmatic Case Studies in Psychotherapy, http://pcsp.libraries.rutgers.edu

Volume 4, Module 2, Article 1, pp. 1-38, 05-12-08 [copyright by author]

more the rumination was delivered in a pressured manner, the more severe the content appeared, and subsequently the more she attention she received.

\section{Persona as a "Sufferer"}

Bridget also recalled that for years growing up her mother modeled self-sacrifice-by working extra hours to give money to family members in need, for example-and that this involved the presentation of a certain degree of suffering, which Bridget then emulated through her own suffering, beginning with the expression of grief for her father's death. Being a "sufferer" appeared to be a major structure undergirding her self-identity and the ways in which her OCD symptoms manifested. By suffering she made atonement with God for her underlying irrational guilt, and selectively ruminating on loss was a way of self-administering that suffering. This was a means of avoidance not uncovered in the earlier CBT facet of treatment. Further, she had believed that suffering made her a "good person," which, upon articulation of this belief, she later negated.

It was not until weeks of exploration (sessions 70 thru 79) in this vein that Bridget's ruminative style began to attenuate. While by the end of treatment (session 79) she had occasional bouts of pressured speech, their overall frequency and intensity had dropped significantly. Exploring secondary gain appeared to be the intervention that affected most change.

\section{Processing the Loss of her Boyfriend and Connection to Her Father's Death}

Bridget reported that the subjective experience of losing Adam was reminiscent of the death of her father, and that there were qualities of her father's character that she either saw in or projected onto Adam. She noted that she tended to idealize her boyfriends in the same manner in which one would idealize a father. Further, she tended to seek boyfriends who seemed larger than life to better facilitate that idealization - her now ex-boyfriend being a college football star, for example. These idealizations in turn led to Bridget's frustration - when the clouds of idealization cleared and she was left disillusioned and angry. They also led toward more observable relationship problems - the failing of her mates to match her idealizations tended to produce unreasonable expectations and demands, which in turn resulted in conflict. For instance, Bridget placed a great deal of weight on her boyfriend's views of her. Subsequently she often found herself checking with and seeking assurance from them, e.g., "Tell me what you think of me," "Do you think I'm a good person?" When the answers to questions such as these failed to meet her needs, she would become excessively frustrated. Underlying the frustration were expectations such as, "My boyfriend's responsibility is to help me create my self image.” Again, Bridget took the initiative in identifying her thoughts, with some expertise gained through her prior CBT training. This she achieved with minimal prompting, such as, "What are you telling yourself when you get that angry?" Once these thoughts were identified we began to test their validity using fairly standard CBT techniques, however in a conversational manner more typical of exploratory therapy. 
Targeting Catholic Rituals as Symptoms of Obsessive Compulsive Disorder:

A Cognitive-Behavioral and Psychodynamic, Assimilative Integrationist Approach

H.A. Garcia

Pragmatic Case Studies in Psychotherapy, http://pcsp.libraries.rutgers.edu

Volume 4, Module 2, Article 1, pp. 1-38, 05-12-08 [copyright by author]

It was during these realizations (between sessions 67 thru 79) that I felt the real grief work around her father's death began. I encouraged the process by asking Bridget to survey the loss in terms of the specific things she was dispossessed of by his dying. She stated that if he had been alive during her teenaged years, she would not have the moral dilemmas concerning sex that she now has. She felt as though she were perpetually floating in her own indecision about what was morally right or wrong, whereas if her father were still alive his guidance could have been the weight that tipped the scales in difficult cases.

I found this aspect of self-discovery especially clinically significant. Her father died at the beginning of her adolescence - more specifically during the emergence of her sexual maturity - by any standards a critical period of her development. Her OCD symptoms also started at this time, which involved themes of guilt and responsibility for his passing and subsequent ritualizing, fusing together several profoundly impacting psychological phenomena: emergent sexuality, loss, guilt, and penitence. Having to contend with the loss of someone who by her descriptions was so intimately structuring to her life, while negotiating the rushing train of adolescence and sexual maturation, while yet at the same time believing oneself to be responsible for her father's death - as per the irrational beliefs originating from her OCD — it is not difficult to understand how sexual guilt could arise and be so interwoven with her sexuality in her adulthood. Conceivably her OCD could have manifested in any number of ways, but it did so in this particular way. This underscores the fact that OCD thoughts and rituals operate within a multiplicity of interlocking heuristic constructs - such as sexual identity, self-esteem, interpersonal connection, the intrinsic need for warmth, nurturance and to be parented — and that intervention can ripple across all these realms.

\section{"Parenting” Dynamics in the Therapeutic Relationship}

The need to be parented became visible in our working relationship. I had noticed on many occasions my own experiencing warm and parental feelings toward Bridget, with a pull to "re-parent her." When I explained the psychodynamic concepts of transference and countertransference, including my experience of working with her, she quickly agreed and pointed out that she had used the treatment in ways evocative of her relationship with her father. She stated that the biggest void created by her father's death was his guidance. She believed that if he was still living he would have guided her through the dating process by screening out unacceptable boys or by giving her advice about boys she was dating. As with sex, his absence had left her in a perpetual state of indecision about boys and contributed to her ruminating about her relationships. She reported that she checked in with me about relationships in the same way she imagined she would have checked in with her father if he were still living. As an understanding of the need for checking and assurance was necessary to delineate the roles she played in intimate relationships, I felt this was an important discovery. To link this discovery to our earlier CBT work in Phase 1, I also pointed out that reassurance-seeking is a characteristic feature of OCD and therefore could be a function of avoidance. I suggested also that she evaluate her relationships for inappropriate or excessive reassurance-seeking. Clearly, embedded in her need for a father figure was a want for reassurance. It was also apparent that this is what she often sought from me, friends and family, sometimes to an excessive degree. 
Targeting Catholic Rituals as Symptoms of Obsessive Compulsive Disorder:

A Cognitive-Behavioral and Psychodynamic, Assimilative Integrationist Approach

H.A. Garcia

Pragmatic Case Studies in Psychotherapy, http://pcsp.libraries.rutgers.edu

Volume 4, Module 2, Article 1, pp. 1-38, 05-12-08 [copyright by author]

Soon into our explorations of the loss of her father I suggested that we try the "empty chair technique" to make more explicit the unmet needs left by her father's death, for example: "I miss___about you; if you were still around I would have_; or since you've been gone I've had__ _ missing from my life.” This tapped at something of very deep meaning for Bridget. While she had previously claimed she had already come to terms with her father's death, she cried for the first few minutes of the exercise and reported a sense of catharsis afterward. Unfortunately, however, she was unable to complete this task, stating that she felt too overwhelmed with emotion at the time. Since this was near the end of treatment, we did not get another opportunity to revisit the issue.

\section{$\underline{\text { Termination }}$}

Overall, therapy was conducted weekly during $2 \frac{1}{2} 2$ academic years (the client generally took the summers off) for a total of 79 sessions. Throughout all our sessions, I felt there was a very solid therapeutic alliance between us, and she maintained her motivation for treatment. She regularly attended sessions and was predictably active and engaged in the therapy process. When she had manifested challenging behaviors during our sessions, such as over-compliance or pressured speech interfering with two-way communication, she was open to productively exploring these behaviors of therapeutic exploration. The termination process generally went smoothly, with Bridget verbalizing her ownership of the gains she had made during therapy and her feeling that she was ready to function on her own after the therapy ended. Further, the termination process highlighted the quality of the therapeutic relationship and afforded a good opportunity to work with transference issues related to the loss of her father as she managed emerging emotions when faced with the end of treatment, and thus the end of my role with her as a care provider. Interpreting the transference, and bringing to light her tendency to in some respects create surrogates in her relationships with men, imparted to Bridget a sense of emotional independence and control, as she felt better able to resist compulsions to repeat similar transferences with others. She also reported that this aided her ability to confidently end treatment, although with some degree of fear about the future, and still not without experiencing a sense of loss that was streaked with the deep pain of the death of her father. Compared to her mastery of her obsessions and compulsions, it was this fear of the future, and of uncertain grounding in her relationships, that was most unresolved by the end of treatment. Bridget reported that she would likely continue therapy in the future after a period of time.

\section{THERAPY MONITORING AND USE OF FEEDBACK INFORMATION}

I collected the quantitative scores reported in Tables 1-3, which were used for monitoring, but only in Phase 1 of the treatment. Throughout the therapy I did have weekly, individual supervision, which was crucially valuable to me in reflecting on the therapy process in each session, including my own countertransferential responses to Bridget, and on how to proceed in the next session. Also, Bridget's response to the various therapeutic tasks I proposed in the therapy and as homework assignments provided me with feedback as to the degree Bridget was open and motivated at the time to working on particular therapeutic issues. 


\section{CONCLUDING EVALUATION OF THE THERAPY'S PROCESS AND OUTCOME}

\section{Outcome Indicators}

Over the course of the CBT treatment regimen during the first 27 sessions of therapy, nearly all Bridget's OCD target behaviors saw rapid reduction to negligible fear, anxiety, and depression. Specifically, Table 3 shows that on the YBOCS and Beck Depression Inventory, Bridget showed a decrease from initial clinical levels of obsessions, compulsions, and depression of 8,10 , and 14 , respectively, to nonclinical levels at the end of the 27 weeks in therapy of 4,2 , and 3, respectively. The results of "SUDS" symptom monitoring measures at intake and the end of CBT treatment are presented in Table 2. These show a substantial decrease in Bridget's ratings from all but one in the 4-8 range at the beginning of therapy to all in the $0-2$ range at the end of therapy.

Bridget's ritualizing in response to all targeted situations was largely eliminated by the end of treatment. Items on the compulsion rating scale of the YBOCS are Likert-type and address average occurrence across the previous week of the following items: the time spent ritualizing, interference from compulsions, distress produced by the compulsions, resistance to compulsions, and attempts at control over compulsions. Bridget's score of "2" on the YBOCS indicated a positive endorsement on only the latter two items. The obsessions that remained included crossing for ambulances or when her brother went out at night. Bridget reported this was not geared toward neutralizing obsessive thoughts, but was part of her religious beliefs. She reported using the behaviors of her family as a gauge, meaning that she did not exceed the frequency of crossing behaviors that family members performed in similar situations. By the end of treatment all other praying conformed to situations more typical of her family culture-e.g., at bedtime, before meals, and at church.

Bridget reported that by the end of treatment she had more insight into her relational style and that she felt more in control over her emotional reactions to events occurring within relationships. More specifically, she reported a growing awareness of patterns of conflict within relationships that were influenced ostensibly by her early learning history, much of which related to the unmet needs left by the death of her father. Although by the time treatment ended she was not in a new relationship, Bridget reported feeling capable of resisting checking behaviors with future boyfriends. She also reported that she would be able to contain her style of pressured with friends by finding new ways to elicit social support, such as by asking for it more directly.

\section{Reflections on the Therapy Process}

\section{The Role of Cognitive Restructuring in Phase 1}

In retrospect, with this case, it seems that I could have effectively dispensed with the cognitive restructuring component of the Phase 1 treatment altogether with the same end results with regard to Bridget's more overt OCD symptoms using exposure and response-prevention (ERP) alone. In fact, the cognitive restructuring seemed to be more of a hindrance, serving as 
Targeting Catholic Rituals as Symptoms of Obsessive Compulsive Disorder:

A Cognitive-Behavioral and Psychodynamic, Assimilative Integrationist Approach

H.A. Garcia

Pragmatic Case Studies in Psychotherapy, http://pcsp.libraries.rutgers.edu

Volume 4, Module 2, Article 1, pp. 1-38, 05-12-08 [copyright by author]

another avenue for Bridget's ritualizing. For example, as discussed earlier, Bridget began using the cognitive facet of treatment in a ritualistic manner, such as by silently repeating the cognitive distortion underlying a particular obsession, e.g., "It's just Magnification, it’s just Magnification;” and by ritualizing the rational responses in reaction to self-deprecating cognitions, so that she would repeat over and over (sometimes for hours) statements like, "People usually give me positive feedback, so while I'm not perfect, I'm a good person." At the very least, I would have reserved cognitive restructuring until after implementing exposure and response-prevention (ERP), based on the hypothesis that the reappraisal of her irrational fears initiated by the ERP process would lessen the perceived need for using thought logs to ritualize: for example, “If I don't check, people still don't get poisoned, and I therefore don't need to constantly reassure myself that I'm not a bad person.” On the other hand, in my mind cognitive restructuring would be worth salvaging in Bridget's case because of its applicability to other areas, such as interpersonal functioning and depression.

\section{The Degree of Structure and Directness in Phase 2}

My work with Bridget ended prematurely, when she graduated from college and moved to another city. In hindsight, there were a number of things I would have done differently. As I mentioned earlier, in Phase 2 I would have addressed the issue of the secondary gain of her pressured speech much earlier. Addressing the topic opened the door to more focused and constructive sessions, which in turn led to a long succession of self discoveries that eventually tapped into a crucial issue to Bridget's psychology, grieving the irreplaceable loss of her father. At a minimum, addressing the topic made the emotional content of discussion of this issue more tangible and more sustained. If I had done this sooner perhaps I could have aided more in the process of grieving and guided the emotional and interpersonal development that would have accompanied such a process.

I feel very strongly that what kept me from doing so was receiving one message early in my training, which magnified my anxieties as a beginning therapist, namely, that patients' egos are exceedingly delicate, and should be treated as though "narcissistic injury" could trigger regression, treatment-resistance, treatment sabotage, or even decompensation. At that time I felt that exploring attention-seeking would have been something to address slowly and with a great amount of care, and so I therefore waited to broach the topic until later in treatment than I would have liked. What I have learned since in working with a variety of different patients is that with good rapport, most patients without serious Axis II features appreciate frank assessments of their interpersonal style and that delivering such messages directly is something uniquely acceptable in a patient-client relationship. I also feel that this is what gives such messages power - that is, people don’t normally receive such candor outside the therapeutic environment.

The integrative work in Phase 2 with Bridget, while not as structured as CBT, involved the identification of underlying cognitive schema. Further, the Phase 2 work addressed in many ways how those schema impacted her interpersonal relationships and style. Within this endeavor we examined her needs for attachment and the patterns of early learning that shaped the ways she sought to address those needs. Given our time limitations and without the pedagogical commitment to employing a less structured and less direct, psychodynamic format, in hindsight I 
Targeting Catholic Rituals as Symptoms of Obsessive Compulsive Disorder:

A Cognitive-Behavioral and Psychodynamic, Assimilative Integrationist Approach

H.A. Garcia

Pragmatic Case Studies in Psychotherapy, http://pcsp.libraries.rutgers.edu

Volume 4, Module 2, Article 1, pp. 1-38, 05-12-08 [copyright by author]

might have chosen a treatment modality that targeted these issues more deliberately, such as Young's Schema Focused Therapy (Young, Klosko, \& Weishaar, 2003). Some additional structure and directness might well have allowed us to more efficiently target Bridget's interpersonal functioning without restricting the artfulness that I believe such an enterprise entails.

\section{"Healthy” Versus "Unhealthy” Praying}

The most striking ethical predicament of this case was the targeting of ritual behaviors that are part of a religious faith in which prescriptions exist for the performance of those very behaviors in a ritualistic fashion. Coming from a society and set of personal precepts that hold greatly the value of one's personal agency in religious expression, I had a natural unwillingness to immediately rush in and command Bridget to cease and desist all religious ritualizing in the interest of treatment, knocking the cross out of her hand with my CBT manual, as it were. Further, doing so would seem to forego, or at least jeopardize on some level, the elements of religion constructive to emotional well-being, such as: social connectedness and support, a framework of meaning to life, a set of guiding moral principles, hopefulness, structure, and the uplifting experience of spiritual immersion. On the other hand, I did not want to allow pathological ritualizing the opportunity to camouflage itself against the background of religion and by doing so maintain suffering in my patient, since her well-being was my primary moral obligation, and since the mission of my work the alleviation of her suffering.

In fact, dealing with these issues was fairly uncomplicated because Bridget and I agreed on every targeted behavior and obsession, and her view was that these were irrational and not part of her religious beliefs. The issue was therefore handled by conscientiously exploring her religious beliefs and identifying which specific symptoms were acceptable targets. So caught up in the spinning wheel of her OCD symptoms, she scarcely had the mental energy to articulate her stance on these issues in the past. While not being a novel self-discovery, her realizations about her own views were something on the order of, "You know, now that I'm really forced to think about it, I really don't think hearing blasphemy (or having sexual intercourse, or praying only at certain times) is a sin." I imagine much more difficulty in treating a case in which either some or all of the rituals would not seem appropriate for targeting based on the client's religious sensitivities. In such a case, care would need to be taken in distinguishing true conviction versus the mere avoidance of aversive stimuli through ritualizing. The question would then have arisen as to whether to recommend the suspension of Bridget's religious beliefs in the interest of a more successful treatment outcome, or to have proceeded with treatment accepting the fact that Bridget would maintain obsessive-compulsive symptoms within the domain of her beliefs.

My own suggestion is that the best and most thoughtful way to proceed in most cases such as this would be to gauge what normal praying and ritualizing are for her particular religious affiliation, and then ask her to restrict such behaviors only to that forum and/or amount. I believe it would also be within my purview to assess whether a client like Bridget came to her specific affiliation through typical channels (e.g., the established practice of her family or culture) or whether it was adopted more as a function of her OCD. 
Targeting Catholic Rituals as Symptoms of Obsessive Compulsive Disorder:

A Cognitive-Behavioral and Psychodynamic, Assimilative Integrationist Approach

H.A. Garcia

Pragmatic Case Studies in Psychotherapy, http://pcsp.libraries.rutgers.edu

Volume 4, Module 2, Article 1, pp. 1-38, 05-12-08 [copyright by author]

The latter appeared to be the case with Bridget. When presented with this question she openly reported that her religious practices, and preoccupations with issues such as the morality of sexual behaviors, were far in excess of those of her family. As proof of this she offered a conversation with her elderly grandmother, someone who by her very post in life naturally evokes images of old-fashioned, more religiously-influenced thinking, which by Bridget's own admission was true relative to younger family members. During the conversation her grandmother flatly asked Bridget if she had had intercourse with her boyfriend "yet." Blushing and brimming with shock and embarrassment, she could only respond, "Grandma!” Her grandmother's response was that she should enjoy herself while she is "still young and beautiful”.

The praying behaviors, however, were the most difficult to address. Clearly if one wishes to maintain an objectivity as a clinician one has to proceed with thoughtfulness and self examination, particularly in presuming to ascribe labels of "healthy" and "pathological" onto a behavior such as praying, even if only for heuristic purposes. But, again, Bridget was thoughtful about these issues and was able to entertain the notion of two different types of praying, just as she was able to consider the potential influence of OCD on the practice of her religion.

An early consideration in psychology was that certain religious practices - like the practices of any other social entity in which there exists behavioral prescriptions - self-select for particular pathologies. From this perspective, religion offers a socially acceptable outlet for the performance of ritual behaviors and therefore OCD sufferers would be drawn to religion as a socially acceptable outlet for an existing or developing pathological behavior. This concept was described as early as Sigmund Freud. In a criticism of what he recognized as the pathological aspect of religious zeal, he argued that:

It has repeatedly been pointed out (by myself and in particular by Theodore Reik) in how great detail the analogy between religion and obsessional neurosis can be followed out, and how many of the peculiarities and vicissitudes in the formation of religion can be understood in that light. And it tallies well with this that devout believers are safeguarded in a high degree against the risk of certain neurotic illness; their acceptance of the universal neurosis spares them the task of constructing a personal one (Freud, 1927/1961 p. 43-44).

Psychological research since Freud has also pointed to the connection between religiosity and OCD symptoms. Studies have suggested that intrusive thoughts are fairly normal phenomena that are experienced by an estimated $90 \%$ of the general population (Rachman \& de Silva, 1978). OCD sufferers tend to appraise these thoughts negatively (such as seeing them as overly important) and consequently respond with efforts to neutralize the thoughts produced through rituals, thereby creating a self-sustaining system of obsessions and compulsions through negative reinforcement - the rituals temporarily provide negative reinforcement for temporary relief from the thoughts, but fail to prevent the continuing existence of the thoughts themselves, which appear to be a ubiquitous feature of human phenomenology. Interestingly, the tenets of many religions place strong emphasis on the importance of thoughts and stress other values similar to the cognitive factors implicated in the maintenance of OCD. 
Targeting Catholic Rituals as Symptoms of Obsessive Compulsive Disorder:

A Cognitive-Behavioral and Psychodynamic, Assimilative Integrationist Approach

H.A. Garcia

Pragmatic Case Studies in Psychotherapy, http://pcsp.libraries.rutgers.edu

Volume 4, Module 2, Article 1, pp. 1-38, 05-12-08 [copyright by author]

One study of Italian Catholics found that subjects with higher degrees of religiosity demonstrated more obsessionality and obsessive cognitions than those with lower degrees (Sica, Novara, \& Sanavio, 2002). The researchers point out that some aspects of OCD - particularly an extreme emphasis on controlling one's thoughts, the overimportance of thoughts and perfectionism (domains of cognition believed to be important in the phenomenology of the disorder by the Obsessive Compulsive Cognitions Working Group [1997] as described above) are all precepts stressed in the Catholic religion. Indeed, the authors found that these three symptom domains were associated with religiosity, differentiating more religious from less religious subjects. Similar trends have been found in studies of Protestantism. One such study found that highly religious Protestants had more OCD-related cognitions - as in the above study, controlling one's thoughts and emphasizing the importance of thoughts - than nonreligious subjects (Abramowitz, Deacon, Woods \& Tolin, 2004). The authors point out that this phenomenon is spurred by Protestant doctrine, which specifically holds that having certain thoughts is the same as performing the sinful behavior - adulterous thoughts, for example.

While studies such as these fall short of establishing a direct cause-effect relationship between religious practices and OCD symptoms, Rachman (1997, p. 798) has proposed that "people who are taught or learn that all their value-laden thoughts are of significance will be more prone to obsessions - as in particular types of religious beliefs and instructions.” If someone with a propensity for OCD assimilates a set of precepts that maintains a style of thinking consonant with those implicated in OCD (such as thought-action fusion and the overimportance of thoughts), the message is surely to add force to his or her symptoms. Consider the following passage in Matthew chapter 5 (New Living Translation [NLT] of the New Testament) in the context of sexual impulses, admittedly the domain of Bridget's most disturbing symptomatology:

27 You have heard that the law of Moses says, 'Do not commit adultery.' 28 But I say, anyone who even looks at a woman with lust in his eye has already committed adultery with her in his heart. 29 So if your eye - even if it is your good eye - causes you to lust, gouge it out and throw it away. It is better for you to lose one part of your body than for your whole body to be thrown into hell. 30 And if your hand -even if it is your stronger hand -- causes you to sin, cut it off and throw it away. It is better for you to lose one part of your body than for your whole body to be thrown into hell. (The Journey, 2003)

It stands plainly to reason that cultural institutions emphasizing thinking patterns associated with OCD would be important influences on the expression of its symptomatology, whether that influence relates directly to the frequency and intensity of symptoms, the initial onset of symptoms, or the draw of OCD sufferers already experiencing symptoms to its behavioral directives. However, in this case Bridget appeared to be drawn more strongly toward the religion in which she was already engaged.

There may be other issues about Bridget's attraction to religion worth considering. The depiction of God as symbolic father is practically ubiquitous in Judeo-Christian doctrine, if not most religions. Bereft of the iconic presence of her father - iconic both in the role he held 
Targeting Catholic Rituals as Symptoms of Obsessive Compulsive Disorder:

A Cognitive-Behavioral and Psychodynamic, Assimilative Integrationist Approach

H.A. Garcia

Pragmatic Case Studies in Psychotherapy, http://pcsp.libraries.rutgers.edu

Volume 4, Module 2, Article 1, pp. 1-38, 05-12-08 [copyright by author]

within the family system, and also the ostensibly all-pervading space in our psyches reserved for fathering — she sought to fill the need with a readily accessible proxy. Admittedly, her relationship with God provided her with the missing aspects of fathering such as guidance, security, and a sense of identity. If her symptoms and religious views were a volatile mixture, then this need was fuel on which the flames fed over the course of years. This is not in any way to pathologize religion, but to point out how a clinical disorder can co-opt religion in a pathological fashion.

My work with Bridget helped me more fully understand the complexity of this

phenomenon and of how the myriad of ways our fundamental needs as human beings - e.g., for meaning, belongingness, security, connection, safety, acceptance, self-worth, not to mention for a larger explanation of our place within the workings of the universe - are mutually influencing and are situated within a vast interconnected network of structures difficult to see without careful scrutiny. My work with Bridget has been influential in this process, shaping the conceptualization of work I have conducted since, and shaping my identity both as a therapist and a person. I learned that I can only approach my work as a therapist with a degree of humility. It is only in humility, I believe, that one grasps the complex confluence of the factors and forces just described. And it is only in this understanding that the tools of science are revealed an appropriate context for application.

\section{REFERENCES}

Abramowitz, J. S., Deacon, B. J., Woods, C. M. \& Tolin, D. E. (2004). Association between Protestant religiosity and obsessive-compulsive symptoms and cognitions. Depression and Anxiety, 20, 70-76.

Abramowitz, J. S. (1997). Effectiveness of psychological and pharmacological treatments for obsessive-compulsive disorder: A quantitative review. Journal of Consulting \& Clinical Psychology, 65, 44-52.

American Psychiatric Association (2000). Diagnostic and statistical manual of mental disorders, text revision ( $4^{\text {th }}$ ed.). Washington, DC: American Psychiatric Association.

Antony, M. M., \& Swinson, R. P., (2000). Phobic disorders and panic in adults: A guide to assessment and treatment. Washington, DC: American Psychological Association.

Arkowitz, H. (1997). Integrative theories of therapy. In P. L. Wachtel \& S. B. Messer (Eds.), Theories of psychotherapy: Origins and evolution. Washington DC: American Psychological Association.

Beck, A. T., Epstein, N., Brown, G., \& Steer, R. A. (1988). An inventory for measuring clinical anxiety; Psychometric properties. Journal of Consulting and Clinical Psychology, 56, 893-897

Beck, A. T., Steer, R. A., \& Garbin, M. G. (1988). Psychometric properties of the Beck Depression Inventory: Twenty-five years later. Clinical Psychology Review, 8, 77-80.

Beech, H. R., \& Vaughn, M. (1978). Behavioral treatment of obsessive states. New York: Wiley.

Brown, T. A., Di Nardo, P. A., \& Barlow, D. H. (1994). Anxiety Disorders Interview Schedule for DSM-IV (ADIS-IV). San Antonio, Tx: The Psychological Corporation

Burns, D. D. (1989). The feeling good handbook. New York: William Morrow and Company, Inc. 
Targeting Catholic Rituals as Symptoms of Obsessive Compulsive Disorder:

A Cognitive-Behavioral and Psychodynamic, Assimilative Integrationist Approach

H.A. Garcia

Pragmatic Case Studies in Psychotherapy, http://pcsp.libraries.rutgers.edu

Volume 4, Module 2, Article 1, pp. 1-38, 05-12-08 [copyright by author]

Chambless, D. L., Caputo, G. C., Jasin, S. E., Gracely, E. J., \& Williams, C. (1985). The Mobility Inventory for Agoraphobia. Behaviour Research and Therapy, 23, 35-44.

Emmelkamp, P. M. G., \& Beans, H. (1991). Cognitive therapy with obsessive-compulsive disorder: A comparative evaluation. Behaviour Research and Therapy, 29, 293300.

Emmelkamp, P. M. G. \& Kwee, K.G. (1977). Obsessional ruminations: A comparison between thought-stopping and prolonged exposure in imagination. Behaviour Research and Therapy, 15, 441-444

Foa, E. B., Cashman, L., Jaycox, L., \& Perry, K. (1997). The validation of a self-report measure of posttraumatic stress disorder: The Posttraumatic Diagnostic Scale. Psychological Assessment, 9, 445-451.

Foa, E. B., \& Chambless, D. L. (1978). Habituation of subjective anxiety during flooding in imagery. Behaviour Research and Therapy, 16, 391-399.

Foa, E. B., Steketee, G. S., Milby, J. B. (1980). Differential effects of exposure and response prevention in obsessive-compulsive washers. Journal of Consulting and Clinical Psychology, 48, 71-79.

Foa, E. B., Steketee, G. S., Ozarow, B. (1985). Behavior therapy with obsessive-compulsives: From theory to treatment. In: M. Mavissakalian (Ed.), Obsessive compulsive disorder: Psychological and pharmacological treatment. New York: Plenium Press.

Foa, E. B., Steketee, G. S., Turner, R. M., \& Fischer, S.C. (1980). Effects of imaginal exposure to feared disasters in obsessive-compulsive checkers. Behaviour Research and Therapy, 18, 449-455.

Freud, S. (1961). The future of an illlusion. (J. Strachey, Trans.) New York: Norton (Original work published 1927).

Goodman, W. K., Price, L. H., Rasmussen, S. A., Mazure, C., Fleishmann, R. L., Hill, C. L., Heninger, G. R., \& Charney, G. S. (1989). The Yale-Brown Obsessive Compulsive Scale: Development, use, and reliability. Archives of General Psychiatry, 46, 1989, 10061011

Jacobson, E. (1938). Progressive relaxation. Chicago: University of Chicago Press

Kenny, F. T., Mowbray, R. M., Lalani, S. (1978). Faradic disruption of obsessive ideation in the treatment of obsessive neurosis: A controlled study. Behavior Therapy, 9, 209-221.

Lazarus, A. A. (1992). Multimodal therapy: Technical eclecticism with minimal integration. In J. C. Norcross \& M. R. Goldfried (Eds.), Handbook of psychotherapy integration (pp. 231263). NY: Basic Books.

Obsessive Compulsive Cognitions Working Group (1997). Cognitive assessment of obsessivecompulsive disorder. Behaviour Research and Therapy, 35, 667-681.

Purdon, C. (2004). Empirical investigations of thought suppression in OCD. Journal of Behavior Therapy and Experimental Psychiatry, 35, 121-136

McGinn, L. K. \& Sanderson, W. C. (1999). Treatment of obsessive-compulsive disorder. Jason Aronson Inc: New York.

Messer, S. B. (1992). A critical examination of belief structures in integrative and eclecticpsychotherapy. In: J. C. Norcross \& M. R. Goldfried (Eds.), Handbook of psychotherapy integration, 130-165. Basic Books: New York.

Meyer, T. J., Miller, M. L., Metzger, R. L., \& Borkovec, T. D. (1990). Development and validation of the Penn State Worry Questionnaire. Behaviour Research and 
Therapy, 28, 487-495.

Rabavilas, A. D., Boulougouris, J. C., \& Stefanis, C. (1976). Duration of flooding session in the treatment of obsessive-compulsive patients. Behaviour Research and Therapy, 14, 349355.

Rachman, S. (1997). A cognitive theory of obsessions. Behaviour Research and Therapy, 35, 793-802.

Rachman S., \& de Silva P. (1978). Abnormal and normal obsessions. Behavior Research and Therapy, 35, 233-248.

Riggs, D. S., \& Foa, E. (1993). Obsessive-compulsive disorder. In: D. Barlow (Ed.), Clinical handbook of psychological disorders: A step-by-step treatment manual ( $2^{\text {nd }}$ ed.), 189239. New York: Guilford.

Schacht, Thomas E. (1984). In: H. Arkowitz, \& S. B. Messer (Eds.), Psychoanalytic therapy andbehavior therapy: Is integration possible? Plenum: New York

Schultz, J. H., \& Luthe, W. (1959). Autogenic training: A psychophysiologic approach in psychotherapy. New York: Grune and Stratton

Skean, K.R. (2005). The case of “CG:” Balancing supportive and insight-oriented psychodynamic psychotherapy with a client undergoing intense life stress. Pragmatic Case Studies in Psychotherapy [Online], Vol. 1(3), Article 1. Available: http://hdl.rutgers.edu/1782.1/pcsp_journal.

Sica, C., Novara, C., \& Sanavio, E. (2002). Religiousness and obsessive-compulsive cognitions in an Italian population. Behaviour Research and Therapy, 40, 813-823

Stern, R. S. (1978). Obsessive thoughts: The problem of therapy. British Journal of Psychiatry, 132, 200-205.

Stern, R.S. Lipsedge, M.S., \& Marks, I. M. (1975). Obsessive ruminations: A controlled trial of thought-stopping technique, Behavior Research and Therapy, 11, 650-662.

The Journey (2003). The sermon on the mount. Retrieved September 21, 2005 from: http://nyjourney.com/devotions/devotions.asp?ID=241

Watson, D., \& Friend, R. (1969). Measurement of social-evaluative anxiety. Journal of Consulting and Clinical Psychology, 33, 448-457.

Young, J.E., Klosko, J.S., \& Weishaar, M. (2003). Schema therapy: A practitioner's guide. Guilford Publications: New York 
Table 1. Bridget's Self-Report Questionnaires at Intake

\begin{tabular}{|l|c|}
\hline Scale & Score \\
\hline $\begin{array}{l}\text { 1) Panic Frequency Questionnaire (Antony \& Swinson, 2000): } \\
\text { ** Out of the Blue Panic Attacks: } \\
\text { ** Triggered Panic Attacks: }\end{array}$ & 0 \\
\hline $\begin{array}{l}\text { 2) Yale-Brown Obsessive Compulsive Scale (YBOCS) (Goodman, Price, Rasmussen, } \\
\text { Mazure, } \\
\text { Fleishmann, Hill, Heninger, \& Charney, 1989): } \\
\text { ** Obsession rating scale: } \\
\text { ** Compulsion rating scale: }\end{array}$ & $8^{*}$ \\
\hline 3) Beck Depression Inventory (BDI) (Beck, Steer, \& Garbin, 1988): & $10^{*}$ \\
\hline 4) Mobility Inventory (Chambless, Caputo, Jasin, Gracely, \& Williams, 1985): & $14^{*}$ \\
\hline 5) Penn State Worry Questionnaire (Meyer, Miller, Metzger, \& Borkovek, 1990): & $70^{*}$ \\
\hline 6) Beck Anxiety Inventory (Beck, Epstein, Brown, \& Steer, 1988): & $10^{*}$ \\
\hline 7) Posttraumatic Stress Diagnostic Scale (Foa, Cashman, Jaycox, \& Perry, 1997): & 1 \\
\hline 8) Social Avoidance and Distress Scale (Watson, \& Friend, 1969): & 7 \\
\hline
\end{tabular}

* Indicates score at or above clinical threshold. 
Pragmatic Case Studies in Psychotherapy, http://pcsp.libraries.rutgers.edu

Volume 4, Module 2, Article 1, pp. 1-38, 05-12-08 [copyright by author]

Table 2. Bridget's Subjective Units of Distress ("SUDS") Ratings on Fear and Avoidance in the First and $27^{\text {th }}$ Session

\begin{tabular}{|l|l|l|l|l|}
\hline SESSION & $\mathbf{1}$ & $\mathbf{1}$ & $\mathbf{2 7}$ & $\mathbf{2 7}$ \\
\hline & $\begin{array}{l}\text { RATING OF } \\
\text { FEAR OF } \\
\text { SITUATION }\end{array}$ & $\begin{array}{l}\text { RATING OF } \\
\text { URGE TO } \\
\text { AVOID } \\
\text { SITUATION }\end{array}$ & $\begin{array}{l}\text { RATING OF } \\
\text { FEAR OF } \\
\text { SITUATION }\end{array}$ & $\begin{array}{l}\text { RATING OF } \\
\text { URGE TO } \\
\text { AVOID } \\
\text { SITUATION }\end{array}$ \\
\hline Sexual Situations & 7 & 8 & 2 & 2 \\
\hline $\begin{array}{l}\text { Checking stoves and locks } \\
\text { (i.e., thoughts of the } \\
\text { consequences of not doing } \\
\text { so repeatedly) }\end{array}$ & 5 & 7 & 1 & 1 \\
\hline Brother getting sick/dying & 5 & 7 & 2 & 1 \\
\hline Brother having car accident & 4 & 7 & 2 & 1 \\
\hline Hearing blasphemy & 4 & 4 & 2 & 0 \\
\hline Ambulance passing & 2 & 4 & & 0 \\
\hline
\end{tabular}


Targeting Catholic Rituals as Symptoms of Obsessive Compulsive Disorder:

A Cognitive-Behavioral and Psychodynamic, Assimilative Integrationist Approach

H.A. Garcia

Pragmatic Case Studies in Psychotherapy, http://pcsp.libraries.rutgers.edu

Volume 4, Module 2, Article 1, pp. 1-38, 05-12-08 [copyright by author]

Table 3. Change in Symptom Measures Over Phase 1 of Therapy

\begin{tabular}{|c|c|c|}
\hline & Week 1 & Week 27 \\
\hline \multicolumn{3}{|l|}{ YBOCS } \\
\hline Obsessions & 8* & 4 \\
\hline Compulsions & $10 *$ & 2 \\
\hline $\begin{array}{l}\text { Beck } \\
\text { Depression } \\
\text { Inventory } \\
\text { (BDI) }\end{array}$ & $14^{*}$ & 3 \\
\hline
\end{tabular}

*Note: The clinical levels for these measures are 8 for Obsessions, 7 for Compulsions, and 14 for the BDI, respectively. 